\title{
Young children's analogical reasoning in science domains
}

\author{
Jesper Haglund, Fredrik Jeppsson and Johanna Andersson
}

\section{Linköping University Post Print}

N.B.: When citing this work, cite the original article.

This is the authors' version of the following article:

Jesper Haglund, Fredrik Jeppsson and Johanna Andersson, Young children's analogical reasoning in science domains, 2012, Science Education, (96), 4, 725-756.

which has been published in final form at:

http://dx.doi.org/10.1002/sce.21009

Copyright: Wiley-Blackwell

http://eu.wiley.com/WileyCDA/Brand/id-35.html

Postprint available at: Linköping University Electronic Press

http://urn.kb.se/resolve?urn=urn:nbn:se:liu:diva-79916 


\section{Young children's analogical reasoning in science domains}

Jesper Haglund, Fredrik Jeppsson and Johanna Andersson

The Swedish National Graduate School in Science, Technology and Mathematics Education Research (FontD), Linköping University, Sweden.

Email, corresponding author: jesper.haglund@liu.se 


\begin{abstract}
This exploratory study in a classroom setting investigates first graders' (age 7-8 years, $\mathrm{N}=25$ ) ability to perform analogical reasoning and create their own analogies for two irreversible natural phenomena: mixing and heat transfer. We found that the children who contributed actively to a full-class discussion were consistently successful at making analogical comparisons between known objects provided by a researcher, and some of the children could come up with their own analogies for the abstract natural phenomena with which they interacted. The use of full class and small group settings, shared laboratory experiences of the phenomena and children's drawings as different kinds of scaffolding was found to be helpful for the children's analogical reasoning. As an implication for science education, selfgenerated analogies are put forward as a potential learning tool within a constructivist approach to education.
\end{abstract}

\title{
Introduction
}

Analogical reasoning has been put forward as a key process in human cognition (e.g. Vosniadou \& Ortony, 1989) and as a crucial factor in learning at all ages, including young children (Brown, Kane, \& Long, 1989). The mechanism of learning from new experiences by comparison with what is already known is central to a constructivist perspective on learning. Surprisingly, research has revealed somewhat of a paradox in that it is difficult for participants in psychological experiments to use analogies that the researchers believe would be useful in the given tasks (Blanchette \& Dunbar, 2000). Piaget, Montangero and Billeter (1977/2001) even claim that analogical reasoning is not performed consistently by children until the formal-operational stage, which typically emerges at the age of 11-12 years.

Blanchette and Dunbar (2000) argue that contrasting a reception paradigm with a production paradigm is a way of solving the paradox of analogical reasoning. Within the reception paradigm, teacher-generated analogies are employed by the teacher to provide a 
suitable source domain for the learners. However, the reception paradigm brings along two challenges: firstly, learners are expected to have an in-depth knowledge of the source domain, and; secondly, learners have to identify the appropriate similarities between the domains. In contrast, in the production paradigm the learners themselves create or generate analogies in order to organise what is known and being learnt about a studied phenomenon. Here, it is the responsibility of the learner to identify and evaluate potential source domains. Consequently, the source domain and how it is linked to the target is grasped by the learner by default, otherwise it would not be considered as useful. Within the production paradigm, spontaneous analogies are created by the learner spontaneously, without being cued by a teacher or researcher; the learner comes to think of a suitable source domain without being prompted to do so (May, Hammer, \& Roy, 2006). Self-generated analogies are created by the learner when prompted by a teacher or a researcher, but the learner is still active in exposing new source domains and mapping them to the target domain (Blanchette \& Dunbar, 2000). In a previous study, we investigated the use of self-generated analogy for thermal phenomena involving the concept of entropy among physics pre-service teachers (Haglund \& Jeppsson, Under review). We found that the exercise of creating one's own analogies encouraged the pre-service teachers to engage in rich discussions with a clear focus on the topic; hence the participants tended to "talk physics" and assumed ownership of their learning in exploring the merits and shortcomings of their analogies.

The thermal domain of physics focuses on different aspects of the concept of energy, including heat as the transfer of energy from a warm object to a cold object. Irreversible physical processes, such as the mixing of two substances or heat transfer, are characterised by the fact that they cannot spontaneously run backwards in time, and by increasing entropy in the considered system and its surroundings, where entropy can be understood as a measure of the disorder of the system and its surroundings or as dispersal of energy ${ }^{1}$. In science education 
research, concepts within the thermal domain have been found difficult to learn (cf. Duit, 2009; Sözbilir, 2003). Due to the fact that involved phenomena such as heat transfer from one system to another often cannot be brought about directly by manipulation by the hands or seen by the eyes, Piaget and Garcia (1977) claim that grasping concepts in the thermal domain is delayed in comparison to concepts in the mechanical domain. The abstract nature of knowledge in the thermal domain makes it suitable for constructing analogies with more concrete phenomena, even though such comparisons are not necessarily easy to make.

In the following, we present a theoretical background to analogical reasoning in general and particularly with regards to empirical research on children's analogical reasoning. After a section on empirical findings regarding children's conceptions of the phenomena of mixing and heating, we relate to the issue of how children may be supported by 'scaffolding' in the form of assistance from adults and an environment conducive to learning. In the present study, we aimed to investigate whether primary school children could generate their own analogies for thermal phenomena. Can young children use analogical reasoning, as indicated by Brown (1989) and Goswami (1992), also in relation to these abstract phenomena and when it comes to generating own analogies, or as claimed by Piaget, et al. (1977/2001), has their capacity for analogical reasoning not yet developed?

\section{The Structure Mapping Theory}

Gentner's (1983) Structure Mapping Theory is adopted in the present study as a theoretical basis for interpreting the nature of analogical reasoning. The purpose of teaching with analogies is to let students learn about a new phenomenon, a target domain, through comparison with a more familiar source domain. An analogy is a comparison between two domains that focuses on similarities between relations, but not on attributes of the individual objects. Gentner (1983) gives the paradigmatic example of Rutherford's analogy, 'the atom is like a solar system', from the field of science and science education. The intended similarity is 
the relation between a central object (the atomic nucleus and the sun, respectively) and smaller objects in orbit around it (electrons and planets, respectively). A focus on attribute similarity, such as implying that the atomic nucleus has to be warm and yellow, since these are attributes of the sun, would not yield an analogy. In table 1, five identified categories of mappings are listed with examples related to the analogy 'the atom is like a solar system' and categorised by mappings of attributes and relations between the two domains.

\section{Table 1}

Kinds of predicates mapped in different categories of domain comparison. Table with examples taken from Gentner (1983, p. 161) and complemented with the 'mere appearance' category from Gentner (1989).

\begin{tabular}{llll}
\hline & $\begin{array}{l}\text { Number of attributes } \\
\text { mapped to target }\end{array}$ & $\begin{array}{l}\text { Number of relations } \\
\text { mapped to target }\end{array}$ & Example \\
\hline Mere appearance & Many & Few & The sun is like an orange \\
\hline Literal similarity & Many & Many & $\begin{array}{l}\text { The K5 solar system is } \\
\text { like our solar system. }\end{array}$ \\
\hline Analogy & Few & Many & $\begin{array}{l}\text { The atom is like our solar } \\
\text { system. }\end{array}$ \\
\hline Abstraction & Few & Many & $\begin{array}{l}\text { The atom is a central } \\
\text { force system. }\end{array}$ \\
\hline Anomaly & Few & Few & $\begin{array}{l}\text { Coffee is like the solar } \\
\text { system }\end{array}$ \\
\hline
\end{tabular}

- In a mere appearance comparison, the focus is primarily on mapping shared attributes or perceived surface similarities, e.g. 'the sun is like an orange', round and yellow.

- In a literal similarity comparison, the source domain and target domain share both attributes and relations, as is often the case when comparisons are made between instances within the same domain, such as two solar systems.

- An analogy focuses on mapping of relations between two domains, but not on mapping of attributes of the involved objects. Discrimination between an analogy and a literal similarity is not a clear-cut issue, but they can be seen as two extremes along a 
continuous scale. At the analogy end there is a comparison between domains far apart; the closer the domains are, the more the literal similarity character comes to dominate.

- An abstraction involves mapping of relations rather than of attributes. In contrast to analogies, the mappings involve only abstract principles: "there are no concrete properties of objects to be left behind in the mappings" (Gentner, 1989, p. 208).

- When domains share neither attributes nor relations, the comparison is an anomaly.

\section{Research on analogical reasoning in young children}

Gentner's Structure Mapping Theory accounts for the structure of analogies and other comparisons in general. We now turn to findings from empirical research on children's ability to perform analogical reasoning. In psychological tests of analogical reasoning, the paradigmatic case is built on the relational structure $A: B:: C: D$, where $C$ has the same relation to $\mathrm{D}$ in one domain as $\mathrm{A}$ has to $\mathrm{B}$ in another domain. For instance, in assessing whether a participant grasps the analogy 'cow':'calf'::'cat':‘kitten', a participant may be asked, 'a cow relates to a calf in the same way as a cat relates to...' and be expected to reply with 'a kitten'. Piaget, et al. (1977/2001) found that children before the formal-operational stage (Stage III which children typically enter by the age around 11 years) did not follow the analogical pattern in a consistent way, when given tasks of the A:B::C:D kind by use of pictures, but often provided answers by mere association, such as replying 'dog' in the analogy above, since cats are associated with dogs. One argument for the children's inconsistent reasoning was that they were prone to accept counter-suggestions from the interviewer, rather than sticking to their first answers.

Criticising Piaget, et al.'s (1977/2001) conclusions, subsequent studies in cognitive psychology (Brown, 1989; Goswami, 1992, 2001) have shown that analogical reasoning is accessible to younger children, if the domains are familiar and the children have understood the task. Goswami and Brown (1989) devised a "game board" with empty spaces for pairs of 
pictures in the form $A: B:: C: D$, of causal relations, such as a knife cutting an apple, which was known to be understood by children of 3 and 4 years of age. They found that children of 3,4 and 6 years of age were able to give the correct answers, and thereby had understood the analogies, even though the percentage of correct answers increased with age. Goswami (1992) concludes that hints to use analogies is a favourable factor for the success in analogy tasks. In addition, children can be taught to use analogical reasoning, after which the probability that they will apply it increases in relationally similar problem-solving scenarios (Brown, et al., 1989) as well as in relationally different scenarios (Brown \& Kane, 1988). In a developmental perspective, Gentner and Toupin (1986) found that both 5-7-year-olds and 8-10-year-olds were sensitive to whether similar animals were playing similar roles or different ones in being able to retell a story. However, only the older group of children benefited from adding systematicity to the original story, in the form of relevant information about the main character of the story (e.g. the chipmunk was jealous, rather than good looking) and a concluding moral. In conclusion, "children, at least by the age of 8 , can use higher-order constraints to help keep the lower-order predicates straight" (ibid. 1986). Based on these and previous findings, Gentner (1989) suggests that there may be a relational shift in the reasoning of children, from a reliance on surface (or attribute) similarities of 5-year-olds to a recognition of relational structure among 9-year-olds.

The value of using analogies in teaching has been long recognised in science education research, but also its potential pitfalls, such as learners' focusing on unintended similarities (e.g. Duit, 1991). To avoid the pitfall that an individual analogy focuses only on limited aspects of a phenomenon, Spiro, Feltovitch, Coulson and Anderson (1989) have proposed that multiple analogies be used in a complementary way when learning about complex phenomena. Most empirical studies have concentrated on older students, but there are examples of studies in the use of analogies also in the teaching of younger children. Chiu and 
Lin (2005) studied student learning of electric circuits in a fourth-grade class and found that analogies promoted student understanding and helped them overcome their misconceptions. Newton and Newton (1995) investigated the use of analogies in teaching electric circuits among 6-7 year-olds. The children in a test group, that were given a water flow analogy, did not differ in their ability to predict what would happen in the circuit from children in a control group that were not exposed to the analogy, but their explanations were significantly more elaborated and they tended to use comparisons to the water flow model.

Science education research has also explored the use of spontaneous or self-generated analogies amongst primary school children. Mason and colleagues found that fourth grade students could generate their own analogies for air pressure phenomena after practical laboratory exercises (Mason, 1995) and that higher learning gains with respect to such phenomena were achieved amongst fifth graders through self-generated versus teacher generated analogies (Mason \& Sorzio, 1996). May, Hammer and Roy (2006) argue that spontaneous analogy is a capability that can be utilised more in education and present the example of Skander, a third-grade student who spontaneously came up with an analogy where a rock falling into lava is compared to ice cubes placed into a glass of water.

\section{Children's conceptions of mixing and heat}

As mentioned, Goswami (1992) emphasises the importance of being familiar with the compared domains for successful analogical reasoning. In order to be able to assess the comparisons generated by the children in the present study, we therefore provide a brief background of early research by Piaget and followers on conceptions of mixing and heat among children in similar age groups.

In relation to the overarching conception of chance, Piaget and Inhelder (1975) studied the conception of mixing among children. They used a seesaw-suspended board containing marbles of two different colours that were initially separated but then mixed as the board was 
rocked back and forth. An initial belief in the preoperational stage I (typically children up to age seven) was that the marbles of the different colours would simply switch places when rocked, but not mix, or follow another non-random pattern. Stage IIA (early concrete operational stage; children about 7 to 9 years old) marked the beginning of the idea of randomness. Here, the children acknowledged that the marbles might mix, but saw this as an unstable unnatural state and argued that the marbles would eventually separate into the initial coloured designations again. In stage IIB (late concrete operational stage; about 8 to 11 years old), the children realised that the marbles would collide and mix more, but had difficulties coordinating trajectories of individual marbles and their final positions in drawings. Finally, by stage III (formal operational stage; 11 to 12 years old), the children could coordinate trajectories with final positions and, most importantly, had grasped the law of large numbers: that it is possible, but very unlikely, that the marbles would return to their original state.

Although a large number of studies have been performed on children's conceptions of heat in educational psychology and science education research, only a minority of them have included children as young as 7-8 years of age. In heat conduction experiments, Piaget and Garcia (1977) found that children in stage I (up to age seven years) were found not to conceptualise heat as something that passes from a warm object to a cold object, but rather as a 'contagious action', influence by proximity. Albert (1978) studied conceptions of heat among children of age 4-9 years by use of clinical interviews, and categorise the conceptions in age dependent stages in the tradition of Piaget. She found that by age seven or eight years, children become aware of the conditional nature of heat, i.e. that hot objects are hot only under certain conditions, such as when you have switched on a plate. By this age, they also start to see the process dimension, for example that something may be warmed up by the sun, and begin to associate heat to their body getting warm when they exercise. In addition, around the age of eight years, they start to differentiate between heat and the object in which the heat 
resides. They now can also talk of heat as spatially located and extended, so that it can move from one object to another.

\section{The role of scaffolding in learning and understanding}

While most studies on conceptions of mixing and heat among young children have been performed within a Piagetian framework by use of clinical interviews, this primarily cognitive perspective has been criticised within subsequent sociocultural traditions. The metaphor 'scaffolding' was introduced in educational psychology by Wood, Bruner and Ross (1976, p. 90) in order to account for the social context of adults tutoring young children in problem solving, going beyond mere imitation: "More often than not, [the social context] involves a kind of 'scaffolding' process that enables a child or novice to solve a problem, carry out a task or achieve a goal which would be beyond his unassisted effort". Such scaffolding may consist of motivating the children, directing their attention and reducing the alternatives of actions. The metaphor of the social context providing scaffolding for the learner fits well with the constructivist metaphor of the learners 'constructing' their knowledge. In addition, it implies that eventually the learner will have appropriated the intended knowledge or skill, so that the scaffolding can be removed. Although introduced by Wood, et al. (1976), scaffolding has come to be associated with the work of Vygotsky in the field of education from a sociocultural point of view, and particularly his theory of the 'zone of proximal development' (ZPD): "It is the distance between the actual developmental level as determined by independent problem solving, and the level of potential development as determined through or in collaboration with more capable peers" (Vygotsky, 1978, p. 86). For instance, Wells (1999, p. 127) sees scaffolding as a way of operationalising ZPD, pointing out three features: "the essentially dialogic nature of the discourse in which knowledge is co-constructed; the significance of the kind of activity in which the knowing is embedded; and the important role played by the artifacts that mediate the knowing." 
Vygotsky (1978, p. 128) emphasises the role of language in the individual's learning and argues that higher psychological structures, such as scientific concepts, appear "first between people as an interpsychological category and then inside the child as an intrapsychological category". Lemke (1990) studied learning of science in terms of appropriating the language of science, of 'talking science'. He describes how a triadic dialogue, where the teacher first poses a question knowing the appropriate answer, students answer the question and finally the teacher evaluates the answer, is very common in the classroom, but does not give much opportunity for the students to talk science. Similarly, in his analysis of discourse in the classroom, Scott (1998) found that it can be divided in two broad types: authoritative discourse, where the teacher is focused on transmitting a thoughtout set of information, and acknowledging only such contributions from the students, often very short direct answers, that support that particular line of reasoning; and, dialogic discourse, where the teacher uses genuine questions, without an answer known beforehand, and opens up for several, possibly inconsistent ideas on a topic, often expressed by the students as extended whole phrases. Going back to Wood et al. (1976), Scott claims that a teacher's responsiveness to a student's learning lies at the heart of 'scaffolding' and argues that this is difficult to achieve in a full class setting. Wells (1999) also describes classroom dialogue and gives examples of how teachers pick up different utterances from students and reformulate them so that an intended idea is made clearer, leading to continued discourse.

Within the field of science education, Schoultz, Säljö and Wyndhamn (2001) draw on sociocultural theories on cognition in their study of children's conceptual understanding of the shape of the earth and gravity. They refer to the features of the ZPD pointed out by Wells (1999) in pointing out limitations of the Piagetian (1929) clinical interview as a method to assess children's conceptions within conceptual change research. First, adopting the perspective on the interview as a 'concrete discursive practice', they claim that 'there is no 
neutral ground on which children's understandings of concepts can be studied. The interview is certainly no privileged context in which the mind can be tapped of its conceptual content in a straightforward manner" (ibid., 2001, p. 116). Instead, an adult interviewing a child is a highly asymmetrical interaction from the perspective of power and control. Further, "[t]he unfortunate point is that psychology and cognitive science, at least until recently, seem to prefer to study people when their thinking is up for inspection rather than when it is used in situated practices" (ibid. 2001, p. 116). In addition, by introducing a globe, an artefact playing the role of a shared object of attention, interviewed children of age 6-11 years managed to account for the shape of the earth and gravity in a strikingly more competent way than found in previous studies using clinical interviews without the support of a globe (e.g. Vosniadou \& Brewer, 1992).

Recently, Ainsworth, Prain and Tytler (2011) have brought to attention the potential value of children making their own drawings as part of science education: enhancing engagement; learning how to represent; support for reasoning; providing learning strategies; and, communication with others. Several of these points fit well within the scaffolding perspective on learning, particularly regarding the communicative function of drawings, providing a complement to spoken and written language. For instance, when asking students to represent the phenomenon of evaporation by drawing and explaining their drawings, Tytler, Prain and Peterson (2007, p. 323) argue that "[ $\mathrm{t}]$ he drawing provides an explicit shared reference point for a collaborative process of clarifying and elaborating ideas.” Brooks (2009) has also recognised the potential in children's drawings for conceptual change. Criticising the Piagetian view that children's drawings directly reflect their cognitive competence, she adopts a Vygotskian perspective in which she sees the drawings as a meaning-making tool in a dialogic engagement with other children and adults. In this vein, Brooks stresses the importance to discuss the drawings with the children to avoid misinterpretations by a teacher 
or researcher. As an example she shows a picture of a tadpole made by a four-year-old girl, where the eyes are protruding from the otherwise black body. From a Piagetian perspective, analysing the drawing in isolation, one would have thought that the girl actually believed that a tadpole looks like this. However, when asked about it, the girl explained that she had to put the eyes there after having drawn the black body, otherwise you would not have been able to see them; a deliberate representational choice. Ainsworth (2010) has found that creating own drawings can be conducive to learning, both if students draw 'self-explanations' and explanations for others, however resulting in very different representations. While the drawings intended for others are clearer and contain more content, the drawings for themselves are less detailed, but include more inferences. In this way, from a scaffolding point of view, drawings may be seen as tools or artifacts that facilitate reasoning and communication. Änggård (2005) has analysed the practice of drawing among Swedish preschoolers from an aesthetic point of view and argues that the children and their teachers have different objectives and standards of what makes a good piece of art. While the teachers encourage imaginative and expressive pictures, showing the uniqueness of the individual child's ideas, the children simply want their pictures to 'look nice' and they have no problems borrowing ideas and pictures from templates, adults, each other, etc. From a sociocultural point of view, this emphasis on reproducing drawings reflects the process of socialisation into the practice of an attracting existing culture.

\section{Research purpose}

The purpose of the present study was to investigate under what circumstances young children can perform analogical reasoning in a school setting. Accordingly, this research was guided by the following overarching research question:

- How does children's analogical reasoning differ between teacher-generated and student-generated analogies? 
The following complementary research questions help provide explanations for the children's differing analogical reasoning in different circumstances:

- How is children's ability to perform analogical reasoning affected by the conceptual difficulty of the target domain?

- How do different kinds and degrees of scaffolding influence children's analogical reasoning?

\section{Methods}

\section{Participants}

The participants were one class $(\mathrm{N}=25)$ of first grade pupils (aged 7-8 years) from a school in a middle class area in Sweden. The children were used to collaborate with each other and partake in group discussions. They had experience of theme-oriented science teaching, including the themes of space and the life cycle of butterflies, during which they had practiced posing 'hypotheses' and observing natural phenomena. They had not been introduced to the concept of 'analogy' or interacted with the phenomena of heat transfer or mixing in school prior to the study. Parents' informed consent was received from all the 25 participating children. In the results, fictitious first names of the children are used to present data.

\section{Research design}

Most studies of young children's capacity for analogical reasoning have been conducted in experimental settings, typically in the form of individual clinical interviews with a researcher (e.g. Goswami \& Brown, 1989; Piaget, et al., 1977/2001). However, we adhere to the view of Schoultz, et al. (2001), that the clinical interview is not the only adequate method to ascertain children's capabilities and, in fact, brings along particular drawbacks. To conduct this study in a setting closer to the children's everyday life, in which the children were familiar with the environment and the communication style of the exercise, two researchers (the first two 
authors) guided the children in small groups in interaction with the phenomena and in the generation of analogies. Our interpretation of 'scaffolding' goes beyond the original emphasis on the interaction between an adult and a child by use of language (Wood, et al., 1976), and includes the interaction between children, the manipulation and perception of physical artefacts and pictorial representations in the form of printed images and children's drawings in a situated practice, in line with Wells' (1999) view on scaffolding as an operationalisation of ZPD. To us, scaffolding means what an individual is capable of doing, when supported by other people and in a constructive environment.

As seen in Figure 1, the research design includes three stages: (1) teacher-generated analogies: to make sure the children have the abilities to carry out analogical reasoning; (2) interaction with the phenomena of mixing of marbles and heat transfer in experiments in the form of 'prediction - observation - explanation' (POE) (White \& Gunstone, 1992); and (3) children's generation of own analogies for the experienced phenomena. A follow-up exercise was conducted two weeks later, where the groups were swapped, a recap of the first session was done and stages (2) and (3) repeated.

\section{Teacher-generated analogies (1)}

During stage 1 (top of Figure 1), the children were introduced to the concept of analogy, by being presented with the pictures in Figure 2 in full class by one of the researchers (JH). The primary goal was to contribute to an answer of research question 1, whether the children could carry out analogical reasoning when given two domains by the researchers. In addition, the exercise was a preparation for stage 3 , where the children would be asked to create own analogies, referring back to the ones brought up in stage 1 . The children were first asked if they could see similarities and differences between the car and the bicycle, particularly with regards to things that "work in the same way", but look different. In this way, the children 
Two groups of 5-6

children each
Two groups of 5-6

children each



First data
collection
session

(2) $\mathrm{POE}$ - heat transfer (FJ)

(2) $\mathrm{POE}$ - mixing (JH)

(3) Children's selfgenerated analogies heat transfer (FJ)

(3) Children's selfgenerated analogies mixing $(\mathrm{JH})$

\section{Follow-up data collection session (two weeks later)}

(1) Recap of first data collection (JH)

(2) $\mathrm{POE}$ - mixing $(\mathrm{JH})$

(3) Children's selfgenerated analogies mixing (JH)
(1) Recap of first data collection (FJ)
(2) POE - heat transfer (FJ)

(3) Children's selfgenerated analogies heat transfer $(\mathrm{FJ})$

Figure 1. Overview of research design

were encouraged to focus on structural or functional similarities, rather than mere appearances, in a language that was meant to be accessible to them, not relying on technical terms, such as 'analogy' or 'relations'. The domains were supposed to be familiar to the children and concrete, in order to facilitate the understanding of what we meant with an analogy, in line with the recommendations of Goswami $(1992)^{2}$. The picture of the walking girl was introduced later as a way to see that domains considered far apart can also have similar structure, e.g. wheels corresponding to legs. Apart from introducing the concept of 
analogy, this session was also used to probe whether the children could follow and elaborate teacher-generated analogies in a full class setting. The session lasted 15 minutes.
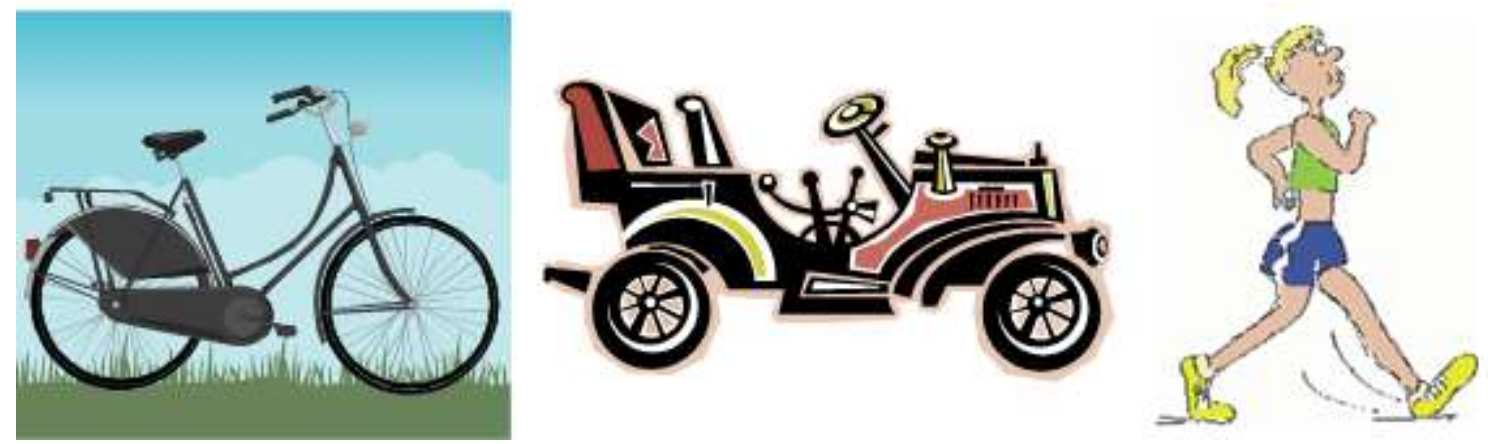

Figure 2. Pictures of a bicycle, a car and a girl shown to the children in stage one.

\section{POE exercises (2)}

In stage 2, the children were divided into four small groups. Two of the groups were introduced to the phenomenon of mixing marbles and the other two to the phenomenon of heat transfer, by means of interaction with physical artefacts. The exercises had the purpose of giving a shared experience of the phenomena, and representations of them in the forms of drawings, which could be used as a 'shared reference point' (Tytler, et al., 2007) or a 'shared object of attention' (Schoultz, et al., 2001) in child to adult or child to child communication, serving as target domains in the subsequent generation of analogies for the phenomena. One group was presented to the phenomenon of heat transfer by interacting with a physical frying pan on a cooking plate and the other group was exposed to the phenomenon of mixing by interacting with a board with marbles that mix (see Figure 3). Both phenomena can be seen as examples of irreversible thermal processes; events that could not spontaneously proceed in the opposite direction in time. In other words, they are characterised by increasing entropy ${ }^{3}$. Following the POE approach (White \& Gunstone, 1992), each of the children was asked to 'predict' what would happen before each stage of the processes. After the children's predictions, we let the children carefully experience and 'observe' what happened and finally 'explain' to each other and the researchers in small group settings. 
In the mixing marbles experiment, the children were presented with a board with marbles, as seen in Figure 3. The board contained seven light marbles and seven dark marbles that initially were divided by a separating device along one of the short sides of the board. The separating device differed slightly from that described by Piaget and Inhelder (1975) in that it was bent, thereby facilitating marbles moving from one half to the other. The board was suspended in the middle like a seesaw, so that the marbles could be rocked back and forth. The children predicted and observed what happened as the board was rocked back and forth first once and then five subsequent times. Then, they were asked to imagine what would happen if it was rocked back and forth 1000 times.

In the heat transfer experiment, the children were asked to feel and observe a plate with a frying pan in different conditions: the plate switched off, the knob switched to 1 and the knob switched to 6 . They were asked to touch the metal base of the frying pan (or feel the 'heat' close to it when warmed up by the plate) and its plastic handle. They also observed how water rapidly boiled off when it was poured into the hot pan. The researcher (FJ) who presented the phenomenon was careful to talk about explain heat as something that is contained in warm objects and that can flow from a warm to a cold object, when asking the children to come up with their predictions and explanations. ${ }^{4}$ For instance, when prompting for predictions of what would happen if the plate was switched off, he could say: "where does the heat go?" The way of talking of heat, as if it were a substance, was motivated by the belief that it would later be easier to come up with analogies where heat was construed as an object, than if it was regarded as a process. However, in line with the recommendations of Wiser and Smith (2008) for this age group, we did not introduce a microscopic, molecular account of matter and involved phenomena, such as heat transfer. 


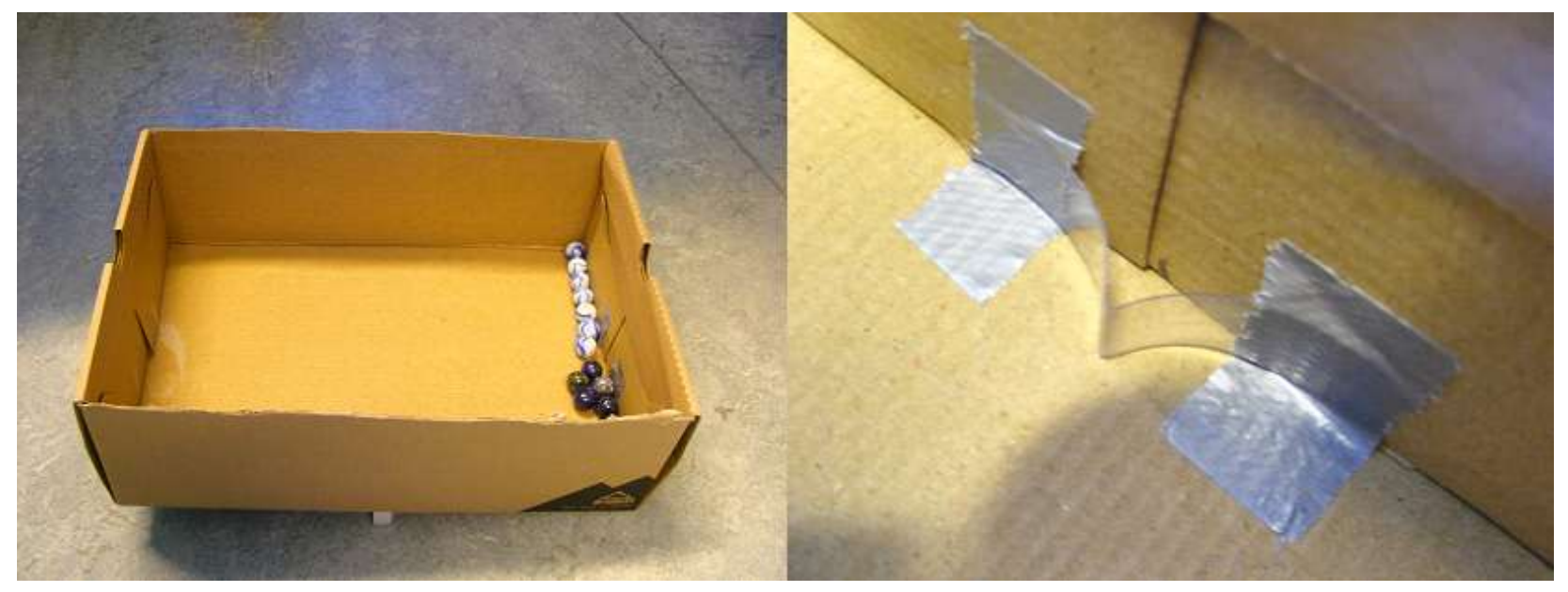

Figure 3. Picture of the board with marbles, used in the POE exercise on mixing marbles.

Marbles of the two colours were initially separated (left). Close-up photo showing the plastic separating device (right).

\section{Generation of own analogies (3)}

In stage 3 , the children remained in the small groups of stage 2 . The primary goal was to be able to assess to what extent the children could generate own analogies for the experienced phenomena. The participants sat around tables and were asked to come up with other situations that 'work in the same way' as the phenomena with which they had interacted, heating of a frying pan and mixing of marbles, just like the bike, car and girl were similar to each other. The children were asked to draw their analogies and then explain them to the researcher and teacher who were present throughout the small group exercises. In this way, the drawings were intended as a meaning-making tool (Brooks, 2009), visual representations of ideas, and, once again, as a 'shared reference point' (Tytler, et al., 2007) in discussions.

The POE and the self-generated analogy sessions lasted for about one hour in total. Following the group sessions, five of the children, whose analogies were identified as particularly interesting, were selected for follow-up debriefing interviews with the researchers, wherein the children described their drawings. 


\section{Follow-up data collection}

A follow-up data collection session was conducted two weeks after the first data collection (Bottom section of Figure 1), where the groups that had experienced heat transfer and mixing exercises were swapped. Five children had been ill in the first data collection session and were distributed among the latter groups. The children were reminded of the introduction to analogies and the previous data collection session, and were now exposed to the same POE and drawing exercises. An additional task was introduced as part of the POE exercise, where the children were asked to fill in templates of the stove and board with marbles (Figure 4) before and after their observations. The children in the heat transfer groups were asked to represent heat and how it flowed by drawing on the provided stove template, with the objectives of capturing their conceptualisation of heat, complementary to their oral accounts, and facilitating comparisons between the source domains and the experienced phenomenon. The children in the mixing marbles groups were asked to draw the trajectories of the marbles on the marble board template, in order to be able to compare the results with those found by Piaget and Inhelder (1975) in similar exercises.
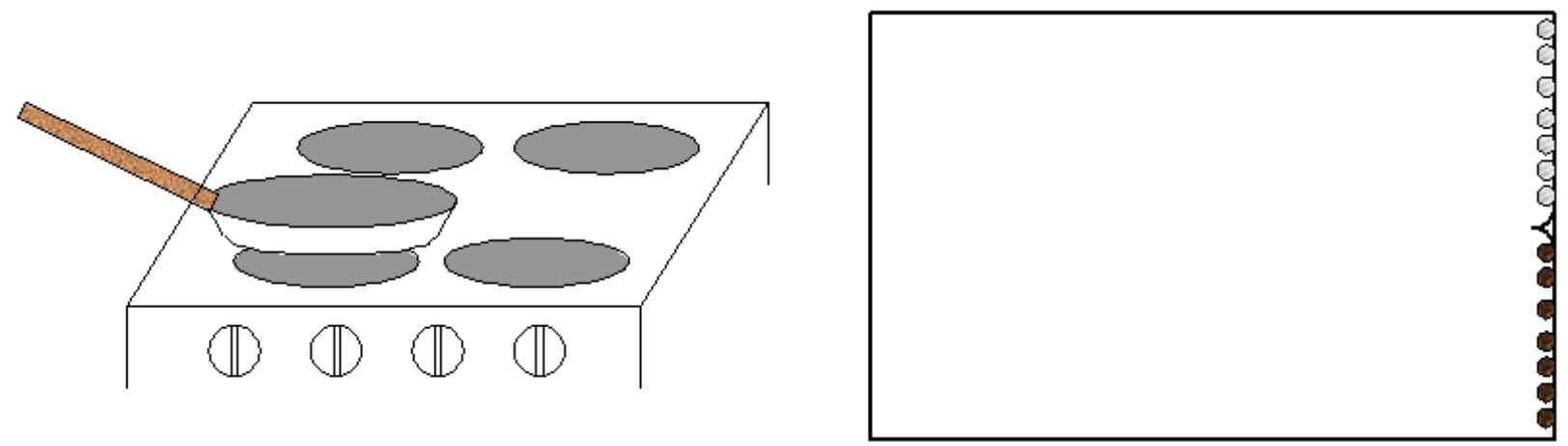

Figure 4. Provided drawing templates of a stove (left) and board with marbles (right) used by the children to represent the phenomena in the second data collection session. 


\section{Data collection and data analysis}

All exercises were video and audio recorded. The researchers watched playbacks of all the video material and selected episodes that span Gentner's categories $(1983,1989)$ in the different settings for transcription, translation from Swedish to English, and further analysis.

Gentner's $(1983,1989)$ categorisation of comparisons between a source domain and a target domain was used to analyse the comparisons. The domains were typically elaborated less by the children than in the physics examples used by Gentner. Often, the focus was on one or two object attributes or one relation, similar to the traditional A:B::C:D analogies familiar from psychological studies on analogical reasoning. Although Gentner (1989) categorises the types of comparisons as sharing 'few' or 'many' predicates of the two kinds, attributes and relations, respectively, she emphasises the kinds of shared predicates and the relative numbers of predicates shared between the domains versus unshared predicates, but not the absolute numbers. Therefore, in our interpretation, sustained focus on one relation only, i.e. mapping the $\mathrm{A}: \mathrm{B}$ relation to $\mathrm{C}: \mathrm{D}$, would qualify as an analogy. In addition, Gentner's description of abstraction is taken from physics, in the form of overarching scientific concepts. In the context of the children's accounts, we have interpreted abstraction as the case where a common function has been identified and named across two domains, in our view adhering to Gentner's description that no concrete properties are 'left behind'. For instance, the steering wheel of a car, the handlebars of a bike, and, possibly, the nervous system of a human being, all provide the shared function of a steering mechanism. Finally, even though Vosniadou (1989) argues that attribute similarities may facilitate the access to interesting source domains and are likely to be positively correlated to structural similarities, we generally regarded analogies and abstractions as successful types of comparisons.

In the results, we present a broad range of examples of comparisons in a narrative form, using transcripts of the children's accounts followed by our interpretation of them and 
categorisation in Gentner's scheme, as well as the circumstances in terms of what kind and degree of scaffolding was provided. In line with Brooks (2009), the children's oral accounts are used together with their drawings in the analysis of their comparisons. In addition, it is brought up how the generation of one comparison relates to the generation of other comparisons, both by the same child in different circumstances and across children.

\section{Results}

Our general impression was that the participating children were cooperative and inventive throughout the exercises. The estimated difficulty of the individual tasks and degree of scaffolding provided to the children, based on the design and outcomes of the exercises, are plotted in Figure 5. While the teacher-generated comparison between the vehicles in the introduction was easy for the children to carry out, the far domain comparison between a vehicle and a girl was more challenging. Similarly, accounting for the phenomenon of mixing introduced the difficulty of the dynamics of the moving marbles, in relation to the still images of the car and the bicycle, and generating analogies for the phenomenon involved mappings, yet another challenge. Finally, accounting for the phenomenon of heat transfer, and particularly coming up with analogies for it, were the most difficult tasks. Due to the fact that you cannot see heat transfer, it is a more abstract process and therefore more difficult to grasp. When it comes to scaffolding, the approach of providing the domains in the form of pictures and discussing them in full class with the children in the introductory session is seen as giving more extensive scaffolding than in the following POE and analogy generation exercises. In addition, during the tasks where the children generated own analogies, increasingly more explicit instructions were given, along the lines of 'other things that work in the same way' and 'on your drawing, what corresponds to the frying pan?'. Finally, Figure 5 also conveys the additional scaffolding provided by FJ in the POE exercise on heat transfer in the form of 
talking about heat as a flowing substance, which did not have a direct counterpart in the POE exercise on the mixing marbles.

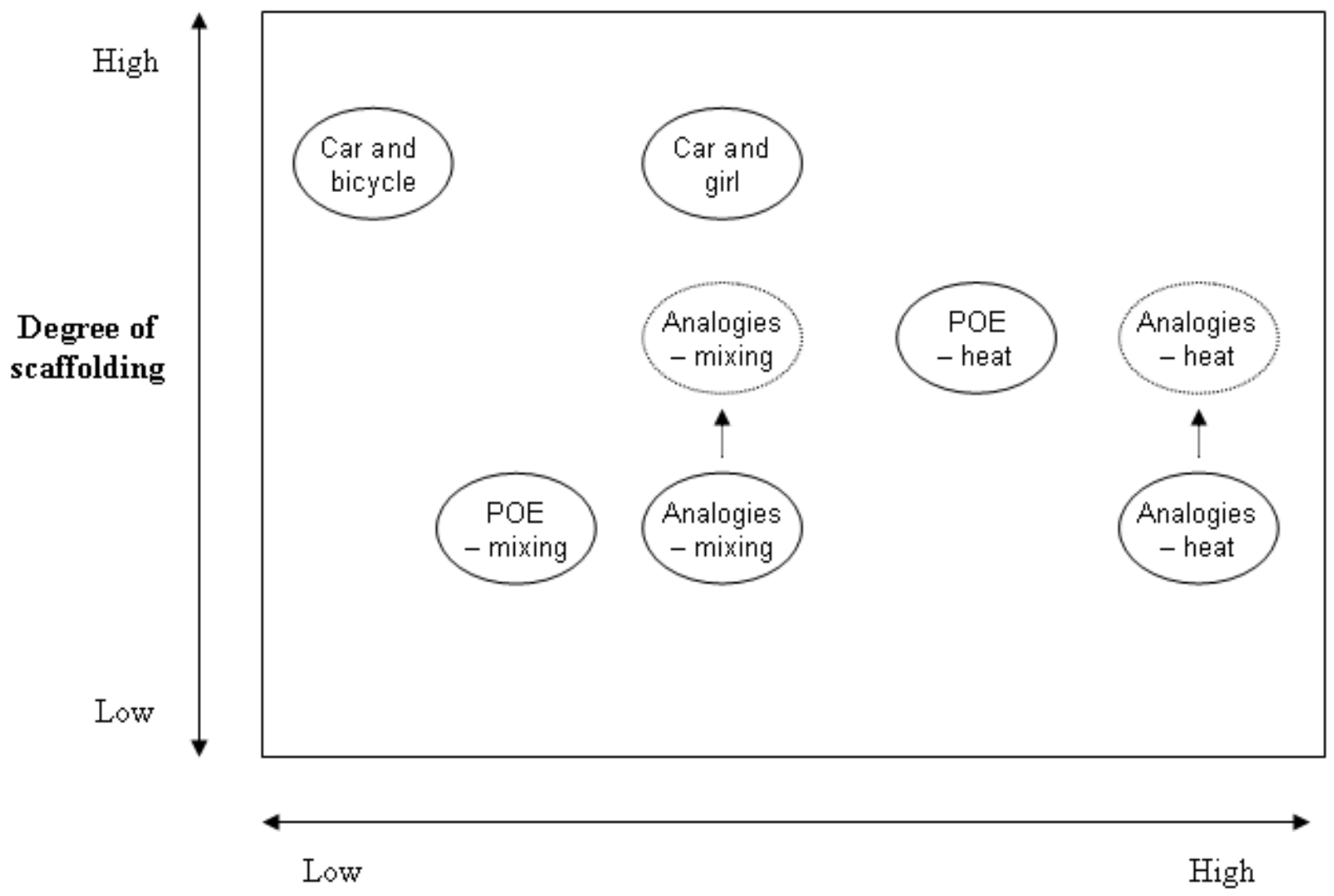

Challenge in content/task

Figure 5. The estimated difficulty of the individual tasks, plotted against the degree of scaffolding provided to the children.

As a collective, the children generated comparisons of all types described in Gentner's (1983, 1989) categorisation system, including analogies, both in the teacher- and self-generated modes, although not very successfully when it comes to self-generated abstractions. An overview with one example each of the different types of comparisons in the three settings is provided in Table 2. Justifications for the classifications and the circumstances under which the comparisons were generated are elaborated in the rest of the results presentation.

Table 2 
Examples of comparisons identified in the three types of settings: teacher-generated analogies from the introduction and self-generated analogies after the POE sessions.

\begin{tabular}{llll}
\hline & $\begin{array}{l}\text { Teacher-generated } \\
\text { analogies }\end{array}$ & $\begin{array}{l}\text { Self-generated comparisons } \\
\text { - mixing }\end{array}$ & $\begin{array}{l}\text { Self-generated } \\
\text { comparisons - heat }\end{array}$ \\
\hline Mere appearance & None identified & A marble is round like a clock & The sun is warm \\
\hline Literal similarity & $\begin{array}{l}\text { A car's wheels are like a } \\
\text { bicycle's wheels }\end{array}$ & $\begin{array}{l}\text { Pushing marbles with a board } \\
\text { on wheels is like tipping the } \\
\text { marbles on a see-saw }\end{array}$ & $\begin{array}{l}\text { Heating a sauce pan is } \\
\text { like heating a frying pan }\end{array}$ \\
\hline Analogy & $\begin{array}{l}\text { A car's steering wheel } \\
\text { corresponds to a bicycle's } \\
\text { handlebars }\end{array}$ & $\begin{array}{l}\text { Mixing marbles is like mixing } \\
\text { different pieces of fruit in a } \\
\text { fruit salad }\end{array}$ & $\begin{array}{l}\text { The sun heating water is } \\
\text { like the stove heating a } \\
\text { frying pan }\end{array}$ \\
\hline Abstraction & $\begin{array}{l}\text { Both a car and a bicycle can } \\
\text { turn (to change direction) }\end{array}$ & $\begin{array}{l}\text { Mixing marbles is like mixing } \\
\text { water and soil into mud }\end{array}$ & None identified \\
\hline Anomaly & $\begin{array}{l}\text { A person's heart } \\
\text { corresponds to a car's petrol } \\
\text { (misled by researcher) }\end{array}$ & None identified & $\begin{array}{l}\text { The heat trying to reach } \\
\text { the handle is like a snail } \\
\text { (misled by researcher) }\end{array}$ \\
\hline
\end{tabular}

Overall, some of the children generated their own analogies and abstractions, although it is difficult to pin-point how many of them, given the group work setting of the exercises. Other children concentrated on the tasks, but did not manage to create analogies. Instead, they focused on attributes and came up with mere appearance comparisons or literal similarities, or were preoccupied making their drawings 'look nice’ (Änggård, 2005).

\section{Interpretation of teacher-generated analogies}

As mentioned, the children were introduced to the concept of analogy by using images of a bicycle, a car and a walking girl (see Figure 2) in full class in stage 1 of the research design (see Figure 1). The introduction was led by $\mathrm{JH}$, one of the researchers, and the discourse can be characterised as primarily of the authoritative kind, with frequent use of triadic dialogue. For instance, when one of the children brought up that you actually can push a bicycle backwards with your feet when you ride it, this line of reasoning was deemed distractive and not encouraged by JH. Below, the children's comparisons across the domains are shown in chronological order, by use of Gentner's $(1983,1989)$ classification. 


\section{Literal similarity}

First, the children were shown the images of the bicycle and the car and JH told that they were going to talk about how things can be similar and different at the same time. It can be seen as a kind of scaffolding, in the form of the researcher directing the children's focus to something they probably would not have picked up spontaneously. JH further asked in what way the car and the bicycle are similar and Karl replied that "both have wheels", but on the other hand, mentioned that the car has four wheels, indicating a difference to the bicycle. In our view, the wheels have the same function in relation to the vehicle as a whole, both for the car and the bicycle. The wheels also share the attributes of being round and rotating, so the comparison is a literal similarity. Although following the triadic form of dialogue, JH left some room for creativity on the part of the children, since he opened up for any similarities across the domains, and does not ask for counterparts to particular entities.

\section{Abstraction}

After talking about the wheels, Erik brought up that both the car and the bicycle can turn, and JH commented that, in this respect, the vehicles have in common that they "work in the same way". In this example, Erik focused on the common function or purpose of the vehicles, in spite of their quite different appearances. Even though it may not initially come across as a very sophisticated reflection, we see this as a case of abstraction; the identification of the function of enabling a vehicle to turn, assumingly by use of some kind of steering mechanism, is a kind of generalisation or common principle, without bringing up the particularities of the two vehicles and their parts.

\section{Analogy}

Next, in this context of talking about the fact that both the car and the bicycle can turn, Lotta picked up Erik's abstraction and continued the reasoning by bringing up the components of the vehicles that would be involved in such a physical action: 
Lotta: What's it called ... One has... what's it called... like, a wheel... a wheel that you can steer with... and the other... also a wheel...

JH: The car has a steering wheel, precisely.

Lotta: Yes.

JH: What does the bicycle have?

Lotta: The bicycle has...

Anna: Handlebars.

Here it was identified that the similarity that the steering wheel and the handlebars fill the same function, things "that you can steer with", in relation to the car and the bicycle, respectively. Therefore, the comparison between the steering wheel and the handlebar is an example of an analogy between the domains of the bicycle and the car. Following Erik's focus on the steering mechanism as a kind of peer to peer scaffolding, Lotta took the comparison a step further in trying to identify what on the bike corresponds to the steering wheel of the car, but searched for the adequate term. JH stepped in and reformulated what Lotta had just said in the grammatical format ' $\mathrm{X}$ has a $\mathrm{Y}$ ', 'what does the $\mathrm{Z}$ have', which is the typical pattern of the analogy format A:B::C:D. Now Lotta used the same grammatical format ' $\mathrm{Z}$ has a...', at which point Anna was able to fill in the adequate corresponding part, the handlebars. This is an example where an idea is not formed in the individual, but in dialogue between several contributors, one of which is the adult who provides scaffolding in the form of reformulation. Other examples of analogies which appeared when comparing the car and the bicycle were the similarities and differences between the horn of the car and the bell of the bicycle, the seat versus the saddle and the engine corresponding to the pedals.

Next, JH displayed the picture of the walking girl. JH did not explicitly ask for correspondences, but Karl pointed out the difference in that "the human being walks /.../ but the car goes." The spontaneous comment on correspondences across the domains shows that Karl has grasped the main idea of what analogies are. The fact that he picked out this particular comparison indicates that he had identified the common function of moving 
forward, arguably another case of abstraction. In a similar way to the explanation about the steering mechanism above, the children spontaneously brought up the parts involved. Johan mentioned that the girl does not have wheels, but when prompted, three other children pointed out that instead, the girl has shoes, feet and legs. While the analogy between the car and the bicycle was within the domain of comparing vehicles or at least between close domains, the girl represents a more distant domain. The children also saw other correspondences, such as between the clothes of the girl and the casing of the car. Here, in the context of JH leading a classroom discussion, they managed to create an analogy between the girl and the car.

In the beginning of the second data collection sessions in small groups (See Figure 1), two weeks after the introduction, the children were reminded of the pictures of the car, the girl and the bicycle and asked if they remembered the previous exercise. Karolina summed up: "What's it like... the girl had legs.../.../ and the car and the bicycle had wheels, but they are not... they don't look the same, but they have the same function..." It is clear that Karolina recalled the previous session and the emphasis on aspects that do not look similar but have the same function in their different settings. Particularly, the use of the rather technical term "function" had been picked up from the exercise two weeks earlier. The participants were further asked to identify what associated with the girl corresponded to the steering wheel of the car. In another group during the second data collection session, Lotta responded:

Lotta: The arms! [gestures turning movement with upper body]

JH: The arms. Why is that?

Lotta: Because... No, I mean the legs! /.../ Because one can like walk with them ... [gestures walking] and they steer where one is going to.

Here, JH plays an important role in bringing up an entity on the car that does not have an obvious counterpart on the girl, the steering wheel. This initiates a thought process for Lotta that probably would not have occurred otherwise. The initial response of "the arms" may be due to the immediate association of holding handlebars or a steering wheel with your arms, in 
our view an anomaly. JH was not very encouraging and asks Lotta to justify her answer, a typical pattern of response to a less satisfactory student answer in triadic dialogues. Now, Lotta rapidly changed her idea to the steering wheel and handlebars corresponding to the legs, with the justification that they steer where one is going. In this respect, she was successful in drawing a far domain analogy from an inanimate object to a living being.

\section{Anomaly}

Apart from Lotta's short-lived anomaly above, another candidate appeared in the introduction to analogies during the first data collection session after one of the children had pointed out that the car has an engine. JH asked what on the girl corresponds to the engine and Lotta responded with the heart, which $\mathrm{JH}$ encouraged as a good comparison, an analogy. JH then asked if there are other things in the body that also do the same thing, wishing for the children to bring up for example the muscles, but Johan replied: "food", arguing that it "makes you able to run". In our view, when JH cued the children to identify other things that make the girl "able to do things", an abstraction of the situation provided by the researcher, Johan picked up this explicit instruction and proposed "food". However, food does not fill the same role in relation to the girl as the engine does to the car, and they do not share attributes or surface similarities either, so this could potentially be classified as an anomaly. Johan had probably distracted from the idea of finding a counterpart to the engine. In fact, it may well be the case that he did not make a comparison at all, but rather responded directly to JH's question. From this point of view, Johan's response would fall outside Gentner's (1983) classification of comparisons. This case of a child misinterpreting an adult's abstraction gives a contrast to the way in which Lotta managed to form Erik's abstraction of the steering mechanism into an analogy between the vehicles. In order to influence Johan in the intended direction, JH now asked "What is it that you put into the car, so that it is able to do things... which is kind of like food?", presenting the task of finding counterparts in the now familiar A:B::C:D analogy 
format. Johan appropriately responded "petrol", showing that he both had grasped the idea of analogy in general, and was able to apply it the comparison of these objects in particular.

\section{Mere appearance}

No cases of mere appearance comparisons with a strict focus on shared attributes were identified in the introductory session on analogies.

\section{Children's self-generated analogies for mixing marbles}

The phenomenon of mixing was introduced to the children by JH in a POE exercise (Stage 2 in Figure 1), through use of a flipping board containing marbles (see Figure 4). When the board was shown to the participants, two children spontaneously commented in two different groups that the separating device was a "ramp" and "like a jump" for the marbles. This, although not part of the design of the exercise, is an example of spontaneous analogy, with a focus on the function of the device in relation to the marbles.

In this stage, the children were asked to come up with hypotheses of what would happen to the marbles. The discourse now had a more dialogic character, since the researcher acknowledged all children's ideas beforehand as valid predictions of what might happen. The typical prediction was that the marbles would mix increasingly when the board was flipped back and forth, and never return to the initial state of the light marbles being separated from the dark ones. A few of the children expressed a more advanced conception of the phenomenon, that there was a risk or chance, albeit very small, that the marbles eventually might separate again after 1000 flips back and forth.

In the follow-up data collection session, the children were also requested to draw the paths of the marbles on templates, before and after the experiment. The result was highly varied, with some drawings indicating that the dark and light marbles would swap sides and others formed a more chaotic pattern, reminding of a "spaghetti Bolognese" (see Figure 6). However, the drawings of the marbles' trajectories were typically less sophisticated than the 
children's oral explanations and we could not see differences between the children's reasoning in the two data collection sessions, with or without templates, or an effect on their subsequent generation of comparisons.

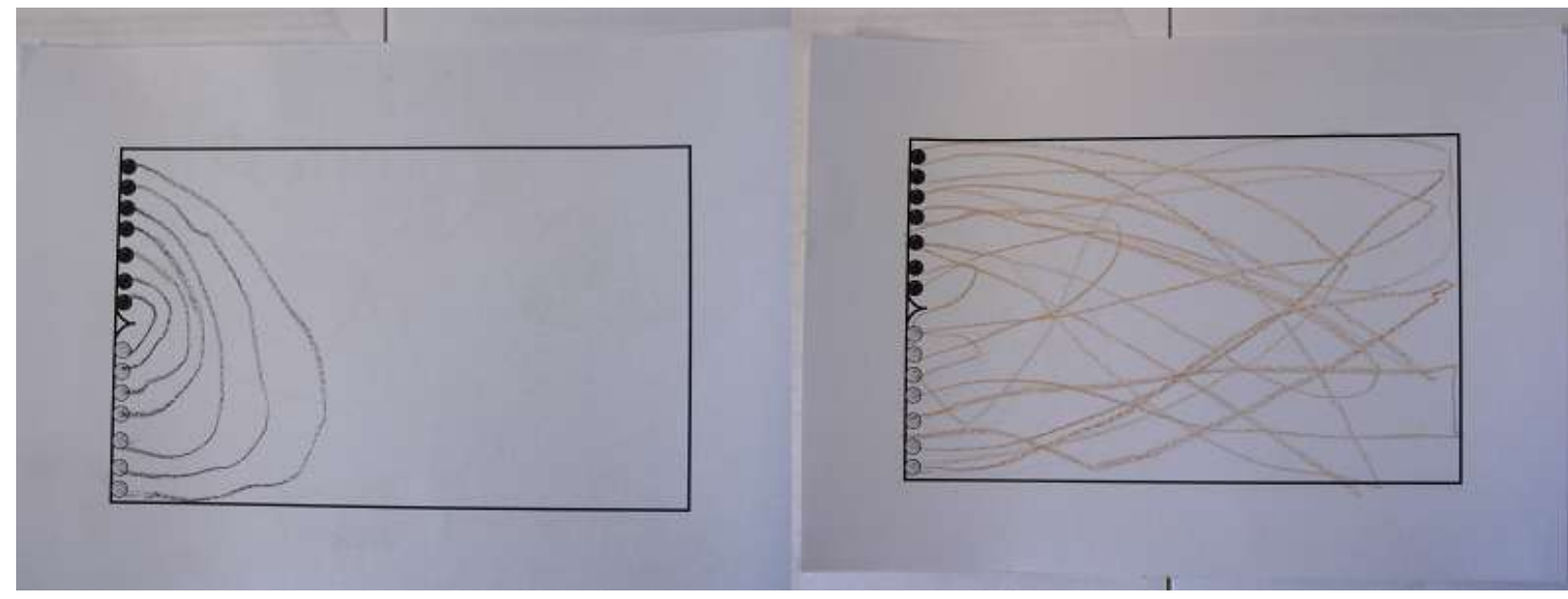

Figure 6. Drawing of marbles swapping sides (left), and "spaghetti" (right), made before the experiments.

After the POE exercise on mixing of marbles, the children were encouraged to come up with situations that are similar to the interacting marbles, in the same way that the car, bicycle and girl are similar to each other. This stage was even more dominated by the dialogic mode of discourse, since all comparisons were initiated by the children, while the role of the researchers and teachers was to encourage the creativity and try to understand the children's comparisons via genuine questions. Examples of the different comparisons that were generated are presented below together with accounts of the circumstances in which they emerged, in the order of how the categories were presented in Table 1 and Table 2.

\section{Mere appearance}

The children at one of the two tables during the first data collection session focused initially on mere appearance mappings (marbles were compared to round objects, e.g. wheels, planets or a clock, and the board were compared to rectangular objects, e.g. a table). In the subsequent 
debriefing session, Maria was selected to be interviewed by JH and FJ. Maria was one of the children who had drawn round objects, such as planets, possibly inspired by the previous astronomy theme in school, and a clock. However, some time into the session with the increasing scaffolding of being asked to find other things that mix, she brought up Barbie dolls and drew the round head of a doll with hair and a face (See Figure 7).



Figure 7. Depicted comparisons to the marble game. Left drawing by Lisa: marbles colliding on marble track (top left), groceries left in an awful mess when dropped (top right) and dodgeball (bottom left); Right drawing by Maria: Round objects are compared to marbles (the round head depicts the Barbie doll) and rectangular objects in comparison with the board.

Maria expressed that she came to think of Barbie dolls when asked to bring up things that mix. In this respect, she was aided in accessing a potential source domain by an explicit instruction, and did not have to work out how it was similar to the target domain. However, when drawing and explaining how the Barbie dolls are similar to the marble experiment, she stuck with her original idea of mere appearance matching in claiming that the commonality lies in the round shape of the head and the round marbles. On the other hand, apart from the focus on the roundness of the head of the Barbie doll, Maria also accounts for mixing of toys in a way that is very similar to the introduction of entropy as disorder in a messy room 
provided in many science textbooks, even at university level. She says that you have to put the dolls in the right places when you tidy up, since they tend to get disordered. In our view, this focus on the attribute similarity of roundness distracts her reasoning and does not contribute to the understanding of mixing as a process in a coherent way. From another point of view, she is not able to make constructive use of the scaffolding provided, that it is the process of mixing that is supposed to be the central similarity across domains.

\section{Literal similarity}

While Maria's mere appearance similarity was potentially distractive, the identified literal similarities in the exercises were less interesting and not interpreted as particularly constructive. For instance, at the beginning of the follow-up data collection, Sven raised two alternative mechanisms for getting marbles to go back and forth on a board, namely by placing the board on wheels and pushing it back and forth horizontally, and having two people at either side of the board that blow the marbles back and forth. With the marbles and the box almost identical to the experiment, and with respect to Gentner's account, we classify this as a literal similarity. In addition, Lena suggested that the box could have water in it, so that the marbles would move slower, another case of literal similarity.

\section{Analogy}

At one of the tables during the first data collection session, none of the children came up with analogies initially. However, by the end of the session, similar to that of Maria's, the participants received increased scaffolding in the form of a cue to think about other things that mix, rather than just being encouraged to draw things that work in the same way. In response, some of the children compared marbles to assorted sweets, plastic fruits (available in the classroom) and crayons, all in a reasonable way. During the debriefing session, Stefan explained his drawing of a transparent jar that contained plastic pieces of fruit: "I put them in order [in layers] and then I shook it and they didn't get in order [became disordered]." Stefan 
has grasped that the pieces of fruit play the same role in relation to the overall phenomenon of mixing as the marbles do in the mixing marbles experiment. In addition, he makes the comparison, even though the pieces of fruit are not similar to the marbles in terms of shape or colour. Therefore, we classify this as an example of analogy.

In one of the groups in the follow-up data collection session, some of the children had many ideas and worked mostly individually. Similar to the preceding outcome that the drawing of trajectories did not seem to influence the children's understanding of the phenomenon, it did not seem to influence their analogies either. Objects that mix, that rock back and forth, and that bounce on walls were brought up. Lisa was particularly inventive and came up with several comparisons, shown in her drawing (Figure 7, left picture). One of her examples was a small drawing that depicts dodgeball, a game where the objective is to hit other players by throwing soft balls at them. Here, Lisa spontaneously pointed out the correspondence between the balls and the marbles and between the people and the board. This analogy was created prior to the children had been instructed to conceptualise other mixing phenomena, so she did not require a lot of scaffolding in order to be able to sort out the correspondences to the experienced phenomenon. When asked about the comparison, she refined the account so that the people that you try to hit correspond to a part of the board, the plastic separator, and later envisioned the event of not hitting people as corresponding to not hitting the separator on the board. Lisa also described a drawing of a marble track, a scenario in which she focused on the aspect of the marbles colliding and becoming crowded "in a row", which would lead to them moving to the other side of the plastic dividing device. Finally, Lisa commented her drawing of a person that had dropped a shopping bag containing groceries on the ground:

Lisa: And then, if you drop things... then it gets like really messy... /... ...they will hit into each other... then they can spill out, if they are groceries... and stuff...

JH: Yes. And how is that similar to the marble game, do you think? 
Lisa: You can say that the groceries... if there is juice... some of it may get on other stuff... and it gets like really messy...

In this excerpt, Lisa focused on groceries hitting each other and causing a mess. Implicitly, the groceries correspond to the marbles that get mixed up. Also this example is reminiscent of popular introductions to entropy as disorder. Taken together, Lisa's three analogies focus on different aspects of the complex process of the marbles getting mixed: bouncing and deflecting; getting crowded and dispersing; and getting "messy".

\section{Abstraction}

By the end of the exercise in the second data collection session, the children in one group were asked if they could come up with other mixing examples. Sven proposed soil that mixes with water to form mud, but the children did not see how this corresponded to the marble game. Perhaps they were unable to realise how the mixing of discrete items is similar to the mixing of continuous substances. In this respect, the word 'mixing' appears to have different meanings in these different types of situations. Similarly, in another group, when asked to find other examples of mixing, Henrik brought up the idea that paints can be mixed, but when probed explicitly, the children could not see how this corresponded to the marble experiment.

\section{Anomaly}

No example of anomaly was identified in the exercise concerned with creating analogies of the mixing marbles phenomenon.

\section{Children's self-generated analogies for heat transfer}

The phenomenon of heat transfer was presented to the children in a POE exercise (Stage 2 in Figure 1). Initially, FJ asked what what happens when you turn the plate on and typical answers were that "it gets warmer" and "it gets boiling hot". Overall, in spite of FJ consistently talking of heat as a substance residing in objects and conduction as heat moving 
from one object to another, the children did not follow this way of conceptualising heating as a process. Instead, they talked of the frying pan getting warm, due to the direct contact with the plate. In the follow-up sessions, the children were also asked to represent the process of heating the frying pan by drawing on supplied templates of the stove. Generally, they found this exercise difficult, but some of the children eventually came up with drawings of spirals going up from the frying pan and spontaneously coloured warm parts as red and cold parts as blue (An example by Patrik is seen in Figure 8). The participants also drew arrows representing the heat transfer from the plate to the frying pan when explicitly instructed to.

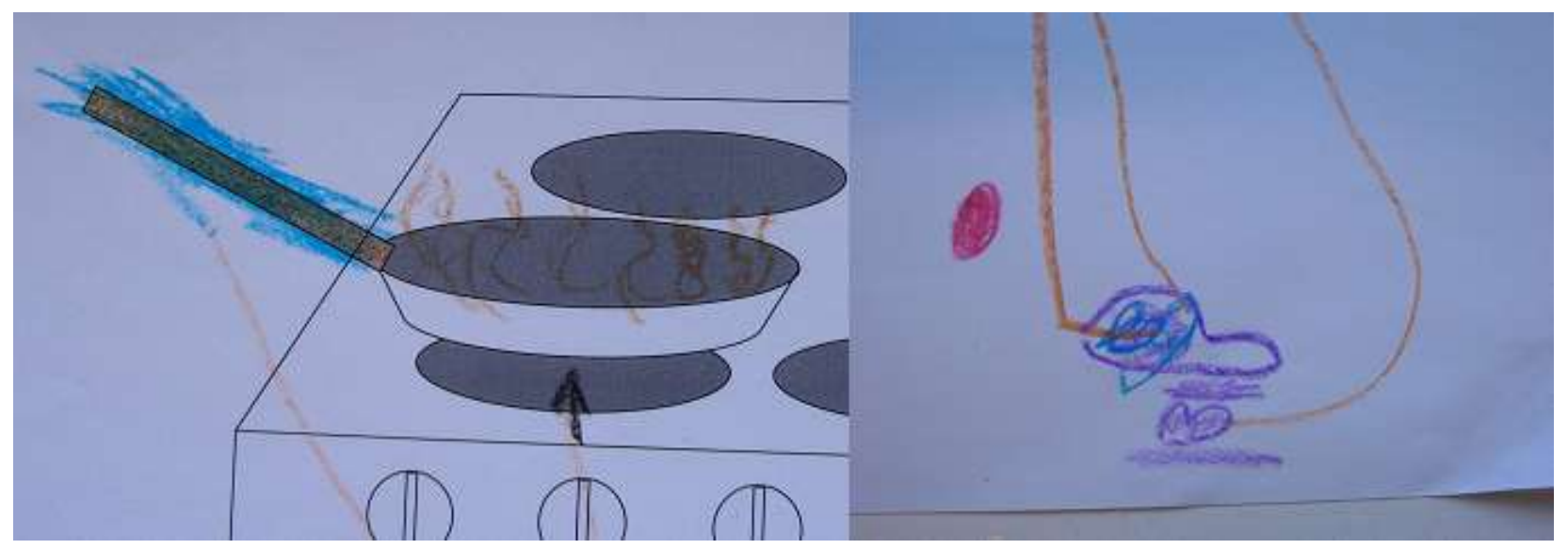

Figure 8. Drawing of heat transfer from the plate to the frying pan by Patrik (left). Drawing of analogy of clothing iron that heats a bead board by Nina, with brown lines indicating corresponding parts of the frying pan and stove (right).

As a parallel to the marble experiment, after the POE exercise on heat transfer, the children were encouraged to come up with situations that are similar to the heat transfer phenomenon, in the same way that the car, bicycle and girl are similar to each other. Examples of the different comparisons to the heat transfer experiment that were generated are presented below together with accounts of the circumstances in which they emerged, in the order of how the categories were presented in Table 1 and Table 2. 


\section{Mere appearance}

After the POE exercise, the children were asked to think of situations that are similar to the heat experiment, in the same way as the car, bicycle and girl are similar to each other (Stage 3

in Figure 1). In the first data collection session, the children typically associated to objects and processes by perceptual similarity, e.g. warm objects and the process of a single object getting warmer (a radiator, the engine of a car, the body of a person when exercising). When generating and drawing comparisons, the children were happy to borrow motifs and ideas from each others and often dedicated some time to finalise their drawings once they had settled for a motif. One instance of influence that goes beyond copying was that drawings of volcanoes were connected to drawings of lava lamps, by reference to the word 'lava'. These examples of borrowing and elaboration of each other's ideas can be seen as a consequence of the social setting in group work, a kind of peer to peer scaffolding. The children also associated to different materials that may combust or not, e.g. the stem of an apple in contrast to the juicy part. We generally categorised such examples as focusing on mere appearance, since no relational structure between objects was involved. However, source domains involving processes relating to a single object are not clear-cut. For instance, the causal relation that suggests that a person that exercises gets warmer may be mapped to the causal relation between switching on a plate and the plate getting warmer, in the form of an analogy. In this respect, the classification would have to be assessed for each different comparison.

In one group during the first data collection session, Axel and another child had started to draw cars, possibly inspired by the previous introduction of the car and the bicycle by the researchers. When FJ joined the table, Lena also started to draw a car. FJ asked them:

FJ: What are you drawing?

Chorus: A car!

FJ: OK. What about the car? 
Lena: Well, the engine is hot. /.../ The cars.../.../ they have a hot engine... but the car doesn't get, like, warm...

FJ: That's right! Why is that...? That you don't burn yourself when you sit in the car?

Axel: That's because the warm [stuff] gets out... /... ...from the exhaust pipe.

The excerpt above serves as an example of the social interaction where the children had inspired each other and worked on a common theme, a car. They contributed to the discussion with input from different perspectives. At the very beginning, Lena expressed that the engine is hot and later, she contrasted this, assumingly, with the rest of the car not getting warm. Although not explicitly comparing the car with the frying pan experiment, she provided an appropriate source domain for an analogy. Axel initially focused on the perception and personal experience of a hot car, but as we see in the excerpt, by the end, he described the process of exhaust fumes getting out of the exhaust pipe, although not further elaborated upon. Overall, the children were often close to depicting correspondences between the frying pan experiment and the car, but did not succeed fully. The failure to create explicit analogies may be due to the complexity of the car with many candidate processes and objects that could be mapped to the frying pan phenomenon. Another explanation could be that the researchers and teachers did not explicitly ask the children to point out the correspondences, which the children may have been capable to do if they had understood that it was of interest.

\section{Literal similarity}

In the second data collection session, Sara came up with a saucepan when FJ asked the children to come up with things that work in the same way as the frying pan on the stove. In discussion with FJ and Sara, Kristina elaborated the similarity to the frying pan, within the same domain of cooking utensils, one of few examples in the study where one of the children engage with the drawing of a peer, beyond borrowing the idea for a motif. Here, the saucepan corresponded to the frying pan and the plate is the same in relation to the two different pans. The examples are so similar, incorporating round containers with a handle on a stove, that we 
categorise this as a 'literal similarity' in Gentner's framework. In our view, in contrast to the literal similarity between the car's and the bicycle's wheels, the comparison of the two pans does not contribute to an increased understanding of this more abstract phenomenon.

\section{Analogies}

A few of the children in the first data collection session made comparisons based on to the process of objects heating other objects, as seen in the following example, where Lisa drew a picture of the sun (see Figure 9, left):

FJ: And you are drawing... is it a big sun?

Lisa: Yes. /.../ because I thought about space... /.../

FJ: What does the sun do up in space?

Lisa: It warms and lights up [inaudible]


Figure 9: Drawing of analogies, including the sun warming water by Lisa (left), and of a balloon that gets punctured by a needle, interpreted from right to left by Karolina (right).

In his way to approach Lisa's drawing, FJ expresses that he is interested in finding out what it represents. FJ poses a genuine question, a characteristic of dialogic discourse, since he does not have an implied correct answer that the child is supposed to figure out. Above the sun, Lisa drew people bathing in water, which apparently got warmed up by the sun, as indicated by spirals over the water. The expression "It warms and lights up" indicates the active role of the sun in warming the water. In addition, even though the plate and the sun share the 
perceptual attribute of being hot, they are not visually similar. From a physics point of view, they also involve different heat transfer mechanisms, i.e. conduction in the case of the plate and radiation in the case of the sun. Therefore we categorise this comparison as an analogy. However, there is no indication that Lisa conceptualises heat as a substance that flows from the sun. It should be noted that Lisa was successful in generating analogies both for the heat transfer and mixing phenomena. A shared characteristic of her approaches to the two exercises is the creation of several comparisons that have been depicted in sketchy collages (compare Figures 7 and 9).

In the follow-up data collection sessions (the bottom half of Figure 1), FJ was more explicit in asking the children to point out correspondences between the heat transfer phenomenon and their analogues by drawing arrows between the counter-parts in the drawings of the two domains, thereby providing more scaffolding than in the previous session. The children's focus in the second data collection session was typically on mapping warm objects to the plate and cold objects to the handle in situations where some objects felt warm and others colder, possibly a consequence of the added exercise of drawing in templates in combination with the children being asked to point out corresponding entities. With this approach, the process dimension of heating was not brought to the attention of the participants as often as in the first data collection session. However, Karolina came up with an interesting example of a process comparison:

Karolina: Someone blows up a balloon with her warm air.../.../ warm air into the balloon. /.../ And then she pricks a hole in the balloon. /.../ So, the balloon... what's it called... explodes... then the warm air gets out [gestures dispersion]

FJ: What would you say that this is the same as?

Karolina: As... what's it called... when you turn off that [the stove] then the warm [stuff] will come [out of the frying pan]. 
In this example, the event of pricking a balloon is compared to turning off the stove (See Figure 9, right). The domains share the structure of heat transfer away from an object after a sudden event, with low attribute similarity. Hence, the comparison is an analogy. In addition, this provides another example of not discriminating between objects and the heat residing in them, but imagining warm "stuff" or warm air as an integrated whole.

Nina provided another example where the process of one object heating another was taken into account. Her drawing (Figure 8, right) is very sketchy and FJ has to ask what it represents:

FJ: What have you done, Nina? What's this? [points to her drawing]

Nina: It's a clothes iron that heats a bead board.

FJ: OK.

Nina: So, that... [points to drawing]

FJ: Draw arrows.

Nina: That...

FJ: What in your drawing is the stove... would you say?

Nina: The board gets warm... [draws arrow between bead board and frying pan] so that is the frying pan. FJ: So that's the frying pan, OK.

Nina: And that [points to the iron and draws arrow to the hot-plate] makes it warm.

Nina compared the experiment setting to a bead board, a spiky board with plastic beads. We categorised this comparison as an analogy, where the relation of one object heating another was shared between the domains. The iron and bead board is an example of a source domain from Nina's everyday experience. However, the most intriguing finding is that she avoided several potential attribute similarities that could confuse the roles of the iron and the bead board. Firstly, the board, as a recipient of heat, is flat like the hot-plate, acting as the heat source in the studied phenomenon. Secondly, she holds the iron, the heat source, in a handle, but holds the handle of the frying pan, the recipient of heat, in the POE exercise. Thirdly, the iron as a heat source is located on top of the bead board, once again in contrast to the 
corresponding plate being beneath the frying pan. From a scaffolding point of view, FJ supported Nina in pointing out correspondences between the objects and their parts, by asking an explicit question on the counterpart of the stove and prompting her to relate them by drawing arrows. In this way, the experience of the experiment, the drawing and the template served as a shared point of reference for them in the continued exploration of the comparison.

Subsequently, FJ tried to expand the analogy and asked if there is something in the iron and bead board that corresponds to the handle of the frying pan, and Nina responded that the water (in the iron) is cold, too. Water is a component of the iron that in our view does not immediately come across as a counterpart to the handle of the frying pan. Water is perceived as cold in general, and may have been selected by perceptual similarity. With the introduction of a third entity in the domain of the iron and the bead board, the analogy became complex and Nina resorted to the more vague association to water by means of attribute similarity, i.e. a mere appearance matching. However, it should be noted that she avoided the association between holding the handle of the iron and holding the frying pan, assumingly because the first serves as a heat source and the latter as a heat recipient. The situation required her to answer something, and water is as good as any answer.

\section{Anomaly}

By the end of the first data collection exercise, FJ intended to widen the field of possible source domains outside heat transfer and finding correspondences to heat having difficulty coming into the handle. He asked the children to think of other things that have difficulty getting to a certain place. Lotta said enthusiastically: “a snail!” In a way similar to how Johan was cued by JH into saying that the engine of a car corresponds to food, Lotta responded directly to FJ's question without there being a relational or attribute similarity. If this example is seen as a comparison, it would be another case of anomaly, but if not, it once again cannot be classified in Gentner's scheme. These two cases of direct questions aiming towards 
generalisations across domains provided by researchers and resulting in misinterpretations can be contrasted with the successful example where Erik's abstraction of steering mechanisms was picked up successfully by Lotta, generating an analogy between the vehicles.

\section{Abstractions}

No examples of abstractions were identified from the exercise on creating analogies related to the heat transfer phenomenon.

\section{Conclusions}

After having presented the findings from the sessions with the children, we now draw conclusions from the study by revisiting the research questions.

How does children's analogical reasoning differ between teacher-generated and studentgenerated analogies?

Overall, the children who contributed actively to the exercises were found to be more successful in performing analogical reasoning in the mode of teacher-generated analogies than when it came to student-generated analogies.

In the context of teacher-generated analogies in full class discourse, the children carried out comparisons of images of a bicycle, a car and a walking girl in a consistent way. The children as a collective had no problems spontaneously pointing out that the steering wheel of a car corresponds to a bicycle's handlebars or that the car's seat fills the same role as a bike's saddle, in spite of dissimilar visual appearances. In this respect, the participants managed to elaborate the comparison between two domains provided by the researchers, with a focus on relational structure. Hence, they grasped and explored this teacher-generated analogy between two similar domains. The children also managed to point out the underlying function of steering mechanisms, which in our view is a case of abstraction. Furthermore, they were also successful in elaborating comparisons between the vehicles and the walking girl, an example 
of a teacher-generated analogy between conceptual domains further apart, across the agentive/inanimate divide. For instance, Lotta realised that the steering wheel of a car may be seen as corresponding to the legs of a girl, in that they help you change direction, rather than settling for the immediate association between the hands and a steering wheel, reminding of the typical anomalous connection between 'cat' and 'dog' from psychological tests of analogical reasoning.

If the children as a collective were very successful in performing analogical reasoning in the context of teacher-generated analogies, the picture was more complex when it came to generating their own analogies for the phenomena with which they interacted in small group settings. This study showed that in certain circumstances, some of the children could generate their own analogies. Certainly, the children were very inventive and came up with a broad range of potential source domains for the phenomena. However, far from all children went as far as generating comparisons that qualified as analogies or abstractions in Gentner's (1983, 1989) classification, and there seems to be large variation in ability between the children in the group. Nevertheless, the fact that some of the children actually managed to generate their own analogies for these abstract phenomena in relation to scientific concepts is indeed remarkable and, as far as we are aware, has not been previously reported before in the literature amongst children of this age group. It should also be noted that there was only one instance of anomaly (or possibly even none) when generating own comparisons.

How is children's ability to perform analogical reasoning affected by the conceptual difficulty of the target domain?

As shown in Figure 5, the tasks given to the children were found to be at different levels of conceptual difficulty. The children were more successful in performing analogical reasoning with regards to familiar objects, i.e. the car, bicycle and a girl, compared to the encountered 
natural phenomena. In addition, generation of participants' own analogies was generally more common in relation to the marble experiment than to the heat transfer experiment.

Regarding the experiment with the mixing of marbles, many of the children conceptualised the general pattern of things that get increasingly mixed and subsequently managed to find suitable source domains for this phenomenon. Concerning the generation of analogies for this phenomenon, several of the children were successful, particularly towards the end of the exercise with the explicit cue of finding other things that mix. The most remarkable example was the complementary analogies for mixing marbles generated by Lisa, including the comparison to dropped groceries.

When it comes to the heat transfer experiment, the children primarily focused on objects being warm or cold. They recognised the contingent character of heat in that objects are not inherently hot, but may be dependent on some kind of action, such as a plate being hot only if you have switched it on. They also associated heat to their bodies getting warm when they exercise and to materials that can burn, e.g. wood. However, they did not follow FJ's example in talking about heat as something that flows from one object to another. Consequently, the majority of the comparisons relating to the heat transfer experiment focused on mere appearance similarities, e.g. certain objects being warm and others cold. In addition, in the cases where seemingly suitable source domains were exposed, such as the car with its warm engine, the situations often became complex, so that the children could not point out the relevant correspondences. Nevertheless, there were some impressive examples of analogies also to this phenomenon, where complexity and distractions were handled skilfully, such as the cases of the sun heating water, the iron heating the bead board and warm air escaping from a punctured balloon. 
How do different kinds and degrees of scaffolding influence children's analogical reasoning?

As depicted in Figure 5, different degrees of scaffolding were provided to the children at different stages of the study. Apart from this, the types of scaffolding also varied throughout the exercises.

In the introduction to analogies in a full class setting, the discourse was primarily of an authoritative kind (Scott, 1998), where JH tried to convey the idea of what an analogy is and guide the children in how analogical reasoning may be carried out, by means of evaluating the counterparts in comparisons that the children suggested, i.e. through triadic dialogue (Lemke, 1990). Even with their sparse exposure to formal schooling, it was evident that the children took advantage of the high degree of scaffolding and have adapted to this kind of lecture discourse and performed successfully.

In the POE exercises, the discourse was of a more dialogical character (Scott, 1998), since the children were encouraged to provide their own predictions and explanations of the experienced phenomena, so the scaffolding was less pronounced. An exception is the idea of heat as a substance, which was provided to the children in a primarily authoritative way, although without much success. Regardless of the amount of scaffolding provided, the children never adopted the view of heat as a substance. Other kinds of scaffolding introduced at this stage were the interaction with the artefacts, i.e. the frying pan on the hotplate and the marble board, and - in the follow-up data collection - the children's drawings of the phenomena in templates. The shared experience of these objects and the drawings were subsequently referred to in the generation of analogies, particularly for the heat transfer experiment.

Finally, when it comes to the generation of own analogies of the encountered phenomena, additional scaffolding to the children's reasoning was given in the form of their drawings of the comparisons, which enabled them to express their ideas and remember them 
when they later discussed them with the adults. Consequently, the discourse was characterised by the researchers and teachers trying to understand the children's drawings and underlying comparisons, hence of a more dialogical kind (Scott, 1998). Our impression was that this was a more challenging form of discourse for the children, compared to the authoritative kind, and we as researchers had a hard time getting the children to explain how the pictures corresponded to the phenomena. The enrichment of the scaffolding throughout the analogy generation sessions, in the form of increasingly explicit instructions, e.g. from 'things that work in the same way' to 'other things that mix', worked in two directions. On one hand, the children were stimulated into making more comparisons, many of which indeed were of the analogy and abstraction kinds. On the other, however, there were also cases where the children misinterpreted the request and lost sight of the overall task of making coherent comparisons across domains, as seen in for example Lotta's slow snail, Maria's Barbie doll, and the fact that the children could not see how mixing of marbles relates to mixing of mud.

\section{Discussion}

Below we discuss the results against the background of the theoretical framework and previous research particularly regarding analogical reasoning among children, and end by pointing towards what implications there may be for science education in general.

\section{Discussion of results}

The findings in the present study regarding the ability to elaborate teacher-generated analogies stand in contrast to the claim by Piaget, et al. (1977/2001) that analogical reasoning is fully developed only by the age of 11-12 years. Instead we provide support for the view of Brown (1989) and Goswami (1992) that considerably younger children are capable of employing analogical reasoning consistently if the source domains are familiar and the task is properly understood. If there is a 'relational shift' from focus on surface features to relational 
structure, as suggested by Gentner (1989), the children that were active in the classroom discussion have made such a shift by the age of 7-8 years, at least as expressed in this context. In addition, the first comparison made by the children was that between the wheels of the car and the bike, which constituted a literal similarity but also led to the subsequent identification of analogous counterparts. This lends support to Vosniadou's (1989) view that attribute similarity may be used in accessing a suitable source domain, and act as a starting point in the search for structural similarities.

Only rarely did the children come up with comparisons that were coded as anomalous, both in the teacher- and self-generated mode of analogical reasoning, and when it happened they had been misled by the researchers. This stands in stark contrast to Piaget, et al. (1977/2001), who found that the odd successful analogical inference typically was accompanied by irrelevant association matches or anomalies among children in this age group. However, we think this contrast in conclusions relies heavily on the interpretation of dialogue between an adult and a child. Goswami (1992) points out that a child following counter-suggestions from an adult is not necessarily an indication of inconsistent reasoning; it may simply show that the child is sensitive to cues from the adult and wants to do a good job in the exercise, reflecting the asymmetrical interaction (Schoultz, et al., 2001). Similarly, in our case, when the children answered in anomalous ways that did not follow the pattern of analogies, they had forgotten about this overarching task and had picked up the latest cue from the researchers in a sensitive way.

In their study of how adults respond to the teacher-generated and self-generated modes of analogies, Blanchette and Dunbar (2000) found that self-generated comparisons tend to rely on relational structures to a larger degree than teacher-generated comparisons do. Similarly, we have found that pre-service teachers elaborated their own analogies to a larger degree than those provided by the teacher (Haglund \& Jeppsson, Under review). In contrast, 
the present study found that the children were more successful in performing analogical reasoning in the context of teacher-generated analogies than in generating their own. We believe that this is not due to a general lack of ability in analogical reasoning, per se. Instead, this is probably mainly due to the difference between the domains that were compared in the different modes. On one hand, the knowledge domains for the teacher-generated analogies were deliberately chosen as easy to grasp in displaying the static structure of familiar objects and their relations, by use of pictures in the psychology tradition of investigating analogical reasoning. On the other, the phenomena of mixing marbles and, particularly, heat transfer and their potential source domains were both abstract processes, where the dynamics of the objects' interaction would have to be conceptualised, in a less controlled group-work setting. However, due to the design of the study, where we changed from the teacher-generated mode to the self-generated mode, increased the level of conceptual difficulty and varied the degree of scaffolding in conjunction, we cannot draw any conclusions on the deciding factor.

The conceptions of mixing of marbles among the children in this study, as exposed primarily in the POE exercises, were slightly more advanced than conceptions among children in the same age group in the study by Piaget and Inhelder (1975). As mentioned, Lisa's three analogies (Figure 7) for the marbles experiment are particularly impressive, and provide three aspects of the process that complement each other in a way similar to that described by Spiro et al. (1989) in terms of multiple analogies. Piaget and Inhelder (1975) justify their claim that children in stage IIB do not yet have a fully developed conception of chance by referring to their not being able to coordinate trajectories and end positions of individual marbles or the interaction between marbles in drawings. Similar to the findings of Piaget and Inhelder (1975), the patterns in the trajectories drawn by the children in our study (Figure 6) were less sophisticated overall than what they described orally. However, relating to Brooks (2009), we argue that a researcher cannot ascertain a child's conception of an object or phenomenon by 
only looking at their drawings of them. Instead, the drawings have to be complemented with the children's accounts as expressed in language, in order for the researcher to attain a deeper understanding of what the drawing represents. Depicting the trajectory of an individual marble as accurately as possible after observation is a difficult task in its own right, requiring skills in both observation and drawing, apart from conceptualising what is happening.

When it comes to the role of the drawings, points can be made also in relation to the children's comparisons to the phenomena. When making drawings reflecting the own comparisons, most of the children seemed more at ease with the objective of making their pictures ‘look nice’ (Änggård, 2005) than making them represent unique ideas. Lisa’s drawing of analogies for the marbles experiment (Figure 7), however, is an exception to this rule with her idiosyncratic pictures. Her images are very sketch-like and could be seen as pointers to or mementos of her much more elaborated mental and verbal representations. This indicates that she made the drawings as a tool for her own thought process, which according to Ainsworth (2010) typically leads to sketchy drawings, but nevertheless may be helpful to learning. Lisa's drawings gives another example in support of Brooks (2009) that a researcher could not appreciate the complexity of an underlying idea merely from looking at a child's drawing. Rather, once again, it served as a 'shared reference point', as described by Tytler et al. (2007), when Lisa elaborated her idea together with the researcher. Nina's drawing of the iron and bead board (Figure 8 ) is another case in point of a very sketchy drawing that hid a considerably more elaborated conceptual grasp of the involved domains and their analogical connections.

In contrast to the findings regarding mixing of marbles, children's conceptions of heat revealed in this study are similar to those found among children of the same age group in the studies by Albert (1978) and Piaget and Garcia (1977). In line with the findings of Albert (1978), the children recognised the contingent character of heat in that objects are not 
inherently hot, but may be dependent on some kind of action, such as a plate being hot only if you have switched it on. In addition, the children's conceptualisation reminds of the process of heating as 'contagious action' (Piaget \& Garcia, 1977), indicated by the fact that they focused on solid objects being in contact and one object heating the other. The idea of heat as flowing from one object to another was not picked up by children, however, in spite of FJ deliberately talking about heat in this way. Consequently, it was difficult for the children to draw such heat flow in the provided templates. Similarly, the majority of the comparisons relating to the heat transfer experiment focused on mere appearance similarities, e.g. certain objects being warm and others cold. In our view, this is an indication that the children did not have access to the conception of heat as a substance, not even within their ZPD (Vygotsky, 1978) as manifested in this context, even though Albert found that such conceptions start to form by the age of 8 years. In all, our findings support the view of Piaget and Garcia (1977) that grasping the concept of heat, which is not directly visible, is conceptually challenging and delayed from a developmental perspective. The relative success in the marbles experiment compared to the heat transfer setting in creating analogies may be due to the fact that the marbles were easy to see, and that the complexity in the different objects involved was lower, making the involved tasks less challenging for the children. In addition, even though the children were familiar with the practice of cooking on a stove, their conception of heat was found to be limited, which according to Brown (1989) and Goswami (1992) is an obstacle to analogical reasoning.

\section{Implications for science education}

Willkening and Sodian (2005, p. 137) claim that the Piagetian view of "preadolescent children as severely deficient, lacking an understanding of the "scientific method"” has traditionally influenced research on scientific reasoning, but recent post-Piagetian research provides evidence for continuity in younger and older children's reasoning and thinking. We believe 
that the traditional view of children as lacking abstract reasoning has also influenced at what age different scientific concepts are introduced in teaching. With this study, we adhere to the view that young children have many cognitive resources that remain largely unexploited in today's teaching approaches, but which could be used and developed in a more constructive and purposeful way; in this case, analogical reasoning. The result of this study is all the more impressive, since it was achieved without extensive training, which has been found to lead to improved abilities in analogical reasoning among children (Brown \& Kane, 1988; Brown, et al., 1989), and in relation to topics outside of regular teaching.

When presenting their analysis of a third-grader's analogy of a melting rock in lava compared with a melting ice cube (which was inventive, but not totally in line with the view of the phenomena according to science), May, et al. (2006, p. 327) got two different reactions in the research community: "Some are immediately impressed with the students' reasoning, commenting about the articulateness and sophistication of the analogy; and some are appalled that the students could not only voice but develop a misconception in this way and have it go unchallenged. We believe the difference in these reactions exposes an important divide of understanding with respect to the nature and purpose of student inquiry." And more (ibid., p. 328): "Part of expertise in scientific inquiry involves the generation and use of analogies. This objective may be harder to measure than whether a student has 'the right answer,' but it is an important one nonetheless." We side with the part of the research community that is enthusiastic about the achievement and creativity shown in this example. We also support the idea that phenomena can be represented in a wide range of complementary ways, rather than accepting only "the right answer", and creative inquiry by means of analogical reasoning may be one approach to create such different meaning-making representations.

If the use of self-generated analogy is to be adopted in regular teaching for this age group, as opposed to in the research setting of the present study, an important additional 
activity would have to be further discussion of the generated analogies: what parts of the domains correspond to each other, what are the merits and shortcomings of the analogies, and where do they break down? This is particularly important for young children. In our previous study (Haglund \& Jeppsson, Under review) where physics pre-service teachers were asked to generate their own analogies for representing thermal phenomena, they assumed ownership of their learning in the form of discussion about how the proposed source domains related to the target domains. In contrast, the children in the present study did not typically discuss their analogies with each other, and their interaction was mainly limited to copying the other children's ideas and drawings. Such dialogue with individual children and in group settings would have to be guided by the teacher ${ }^{5}$. For instance, when picking up Skander's analogy for lava, reported by May, et al. (2006), the teacher first explored the analogy together with the individual child, but later brought in several children in discussing and elaborating it. Similarly, at first glance on the outcome of the present study, it may be seen as a meagre result that not so many of the children generated own analogies, particularly for the heat transfer phenomenon. From the perspective of using individual children's ideas as a starting point for group discussions, however, it might even have been sufficient with one single comparison with potentially rich connections between the domains. For instance, we think that the examples of the car and the clothing iron both qualify in this respect in relation to the heat transfer phenomenon. At the same time, it may be argued that asking children of age 7-8years to come up with own analogies might be better suited for less challenging phenomena than heat transfer in regular teaching. Similarly, the fact that none of the children was capable of relating the mixing of marbles to mixing at a microscopic level, e.g. of mixing soil and water into mud, supports the view put forward by Wiser and Smith (2008) that children in this age group generally are not yet prepared for a microscopic account of matter. 
Finally, from a teaching perspective, the categorisation of mere appearance matches and literal similarities identified by the children as less successful kinds of comparisons may be seen in a different light. If a child identifies a source domain as similar to a target domain in any respect, including perceptual reminiscences or other shared attribute features, this can be seen as a valid starting point for a deeper exploration of the similarity, which can be facilitated by the teacher. As noted by Vosniadou (1989), the access to relevant source domains is often facilitated by attribute similarities. Once again the case of the comparison of the frying pan experiment with different parts of a car, where the relational structure was not attended to by the children, had the potential to be further elaborated with help from a teacher. The crucial issue is that the teacher adopts the production paradigm of learning by exploiting the child's imagination and creativity (Blanchette \& Dunbar, 2000). However, it is not always easy for us adults to understand in what sense a child finds some situation similar to another, but we still argue that it represents a more sympathetic view of education than the traditional reception paradigm with regard to analogy: It is better if teachers have to guess what the children think than vice versa!

\section{Acknowledgements}

We thank the children and teachers that participated in the study. We also thank our colleagues in the Swedish National Graduate School in Science and Technology Education and Pedagogic Practices at Linköping University for useful comments and feedback, particularly Shu-Nu Chang Rundgren for her valuable suggestions of the research design and Konrad Schönborn and Tamer Amin for their thorough reading and suggestions for the manuscript. Finally, we were much helped by the suggestions from three anonymous reviewers and the editor. 


\section{References}

Ainsworth, S. (2010). Improving learning by drawing. Paper presented at the 9th International Conference of the Learning Sciences. Retrieved 9 September, 2011, from http://dl.acm.org/citation.cfm?id=1854587

Ainsworth, S., Prain, V., \& Tytler, R. (2011). Drawing to learn in science. Science, 333(6046), 10961097.

Albert, E. (1978). Development of the concept of heat in children. Science Education, 62, 389-399.

Blanchette, I., \& Dunbar, K. (2000). How analogies are generated: The roles of structural and superficial similarity. Memory \& Cognition, 28(1), 108-124.

Brooks, M. (2009). Drawing, visualisation and young children's exploration of "big ideas". International Journal of Science Education, 31(3), 319-341.

Brown, A. L. (1989). Analogical learning and transfer: What develops? In S. Vosniadou \& A. Ortony (Eds.), Similarity and analogical reasoning. Cambridge, UK: Cambridge University Press.

Brown, A. L., \& Kane, M. J. (1988). Preschool children can learn to transfer: Learning to learn and learning from example. Cognitive Psychology, 20(4), 493-523.

Brown, A. L., Kane, M. J., \& Long, C. (1989). Analogical transfer in young children: Analogies as tools for communication and exposition. Applied Cognitive Psychology, 3(4), 275-293.

Chi, M. T. H., Slotta, J. D., \& De Leeuw, N. (1994). From things to processes: A theory of conceptual change for learning science concepts. Learning and Instruction, 4(1), 27-43.

Chiu, M.-H., \& Lin, J.-W. (2005). Promoting fourth graders' conceptual change of their understanding of electrical current via multiple analogies. Journal of Research in Science Teaching, 42(4), $429-464$.

Duit, R. (1991). On the role of analogies and metaphors in learning sciences. Science Education, 75(6), 649-672.

Duit, R. (2009). Bibliography - STCSE. Students' and teachers' conceptions and science education. Retrieved 10 May, 2010, from http://www.ipn.uni-kiel.de/aktuell/stcse/stcse.html. 
Gentner, D. (1983). Structure-mapping: A theoretical framework for analogy. Cognitive Science, 7(2), $155-170$.

Gentner, D. (1989). The mechanisms of analogical learning. In S. Vosniadou \& A. Ortony (Eds.), Similarity and analogical reasoning. Cambridge, UK: Cambridge University Press.

Gentner, D., \& Toupin, C. (1986). Systematicity and surface similarity in the development of analogy. Cognitive Science, 10(3), 277-300.

Goswami, U. (1992). Analogical reasoning in children. Hove, UK: Lawrence Erlbaum Associates.

Goswami, U. (2001). Analogical reasoning in children. In D. Gentner, K. J. Holyoak \& B. K. Kokinov (Eds.), The analogical mind: Perspectives from cognitive science. Cambridge, Mass: MIT Press.

Goswami, U., \& Brown, A. L. (1989). Melting chocolate and melting snowmen: Analogical reasoning and causal relations. Cognition, 35(1), 69-95.

Haglund, J., \& Jeppsson, F. (Under review). Using self-generated analogies in teaching of thermodynamics.

Jeppsson, F., Haglund, J., \& Strömdahl, H. (2011). Exploiting language in teaching of entropy. Journal of Baltic Science Education, 10(1), 27-35.

Lambert, F. L. (2002). Disorder - A cracked crutch for supporting entropy discussions. Journal of Chemical Education, 79(2), 187-192.

Lemke, J. L. (1990). Talking science. Language, learning and values. Norwood, NJ: Ablex.

Mason, L. (1995). Collaborative reasoning on self-generated analogies: conceptual growth in understanding scientific phenomena. Paper presented at the Annual Meeting of the American Educational Research Association.

Mason, L., \& Sorzio, P. (1996). Analogical reasoning in restructuring scientific knowledge. European Journal of Psychology of Education, 11(1), 3-23.

May, D. B., Hammer, D., \& Roy, P. (2006). Children's analogical reasoning in a third-grade science discussion. Science Education, 90(2), 316-330.

Newton, D. P., \& Newton, L. D. (1995). Using analogy to help young children understand. Educational Studies, 21(3), 379-393. 
Piaget, J. (1929). The child's conception of the world. London, UK: Routledge.

Piaget, J., \& Garcia, R. (1977). Understanding causality. New York, NY: The Norton Library.

Piaget, J., \& Inhelder, B. (1975). The origin of the idea of chance in children. London, UK: Routledge \& Kegan Paul.

Piaget, J., Montangero, J., \& Billeter, J.-B. (1977/2001). The formation of analogies. In J. Piaget \& R. R. Cambell (Eds.), Studies in reflecting abstraction (pp. 139-152). Hove, UK: Psychology Press.

Schoultz, J., Säljö, R., \& Wyndhamn, J. (2001). Heavenly talk: Discourse, artifacts, and children's understanding of elementary astronomy. Human Development, 44(2-3), 103-118.

Scott, P. (1998). Teacher talk and meaning making in science classrooms: a Vygotskian analysis and review. Studies in Science Education, 32(1), 45-80.

Shannon, C. E. (2001). A mathematical theory of communication. SIGMOBILE Mob. Comput. Commun. Rev., 5(1), 3-55.

Spiro, R. J., Feltovitch, P. J., Coulson, R. L., \& Anderson, D. K. (1989). Multiple analogies for complex concepts: Antidotes for analogy-induced misconception in advanced knowledge acquisition. In S. Vosniadou \& A. Ortony (Eds.), Similarity and Analogical reasoning. (pp. 498-531). New York, NY: Cambridge University Press.

Sözbilir, M. (2003). A review of selected literature on students' misconceptions of heat and temperature. Boğaziçi University Journal of Education, 20(1), 25-41.

Tytler, R., Prain, V., \& Peterson, S. (2007). Representational issues in students learning about evaporation. Research in Science Education, 37(3), 313-331.

Wells, G. (1999). Dialogic inquiry: Towards a sociocultural practice \& theory of education. Port Chester, NY: Cambridge University Press.

White, R., \& Gunstone, R. (1992). Probing understanding. London, UK: The Falmer Press. Wilkening, F., \& Sodian, B. (2005). Scientific reasoning in young children: introduction. Swiss Journal of Psychology, 64(3), 137-139. 
Wiser, M., \& Amin, T. G. (2001). "Is heat hot?" Inducing conceptual change by integrating everyday and scientific perspectives on thermal phenomena. Learning and Instruction, 11(4-5), 331355.

Wiser, M., \& Smith, C. L. (2008). Learning and teaching about matter in grades K-8: when should the atomic-molecular theory be introduced? In S. Vosniadou (Ed.), The international handbook of conceptual change (pp. 205-239). London, UK: Routledge.

Wood, D., Bruner, J. S., \& Ross, G. (1976). The role of tutoring in problem solving. Journal of Child Psychology and Psychiatry, 17(2), 89-100.

Vosniadou, S. (1989). Analogical reasoning in knowledge acquisition. In S. Vosniadou \& A. Ortony (Eds.), Similarity and analogical reasoning (pp. 413-437). Cambridge, UK: Cambridge University Press.

Vosniadou, S., \& Brewer, W. F. (1992). Mental models of the earth: A study of conceptual change in childhood. Cognitive Psychology, 24(4), 535-585.

Vosniadou, S., \& Ortony, A. (Eds.). (1989). Similarity and analogical reasoning. Cambridge, UK: Cambridge University Press.

Vygotsky, L. S. (1978). Mind in society: The development of higher psychological processes. Cambridge, MA.: Harvard University Press.

Änggård, E. (2005). Förskolebarns meningsskapande i bildaktiviteter utmanar vuxenvärden (Preschoolers' creation of meaning in image activities challenges the adult world). Paper presented at the ACSIS national conference for cultural studies (ACSIS nationella forskarkonferens för kulturstudier), Norrköping, Sweden, 13-15 June.

\footnotetext{
${ }^{1}$ The metaphor 'entropy is disorder' is used commonly in education, but is also seen as problematic in science education research (cf. Jeppsson, Haglund, \& Strömdahl, 2011; Lambert, 2002).
} 
${ }^{2}$ In fact, as pointed out by Goswami (1992), Piaget, et al. (1977/2001, p. 142) report on a 5-year-old accounting for a similar analogy, bicycle:handlebars::ship:helm: "the steering wheel is what you drive, the handlebars are the same thing", but see this as only a momentary example and not a case of stable analogical reasoning, since the child does not carry out the mapping consistently afterwards.

${ }^{3}$ Formally, the mixing of marbles is not a natural phenomenon and is characterised by increasing informational entropy in Shannon's (2001) sense, but not directly applicable to the physical quantity of entropy.

${ }^{4}$ Speaking of heat as residing within warm objects may come across as an unwise design choice, since a substance-like conception of heat has been identified as a common misconception among students (e.g. Chi, Slotta, \& De Leeuw, 1994) in science education research, acting as an obstacle when introduced to the theory of thermodynamics. In thermodynamics, heat is the process of transfer of energy between systems in thermal contact, from the system with higher temperature to the system with lower temperature, but it is not an attribute of a system. The concept 'internal energy' would be a better candidate as corresponding to 'what resides in warm objects' in the context of thermodynamics, but the introduction to thermodynamics in school is still many years away for the children in the present study and the interpretation of energy in relation to thermal phenomena has been found challenging for much older students (e.g. Wiser \& Amin, 2001). In this study, we regard the idea of heat as residing in warm objects as a useful 'stepping stone' (Wiser \& Smith, 2008) on the way towards an understanding of thermal phenomena in line with the accepted view in science.

${ }^{5}$ Another idea that a teacher could bring up is the connection between the two phenomena of heat transfer and mixing, in that both are irreversible processes, which was not touched upon by any of the children. We did not expect that the children would be able to see connections between the two exercises or phenomena, and such reasoning might be suitable for older students, maybe when introduced to a microscopic account of heat. 